\title{
REVIEWS
}

\section{Chemical targets to deactivate biological and chemical toxins using surfaces and fabrics}

\section{Christia R. Jabbour, Luke A. Parker (D), Eline M. Hutter and Bert M. Weckhuysen $\mathbb{D}^{凶}$}

Abstract | The most recent global health and economic crisis caused by the SARS-CoV-2 outbreak has shown us that it is vital to be prepared for the next global threat, be it caused by pollutants, chemical toxins or biohazards. Therefore, we need to develop environments in which infectious diseases and dangerous chemicals cannot be spread or misused so easily. Especially, those who put themselves in situations of most exposure - doctors, nurses and those protecting and caring for the safety of others - should be adequately protected. In this Review, we explore how the development of coatings for surfaces and functionalized fabrics can help to accelerate the inactivation of biological and chemical toxins. We start by looking at recent advancements in the use of metal and metal-oxide-based catalysts for the inactivation of pathogenic threats, with a focus on identifying specific chemical bonds that can be targeted. We then discuss the use of metal-organic frameworks on textiles for the capture and degradation of various chemical warfare agents and their simulants, their long-term efficacy and the challenges they face.

\section{Pathogens}

Foreign agents, such as bacteria or viruses, that cause disease.
Inorganic Chemistry and Catalysis group, Debye Institute for Nanomaterials Science, Faculty of Science, Utrecht University, Utrecht, Netherlands.

凶e-mail:b.m.weckhuysen@ uu.nl

https://doi.org/10.1038/ s41570-021-00275-4
Throughout our daily lives, our health is exposed to many invisible risks, most of the time unknowingly. These risks can be human-made or natural, present intentionally or unintentionally and differ across the world. Pathogens, such as bacteria and viruses, threaten lives worldwide through the diseases they cause. They can spread through the collective use of common surfaces (such as doorknobs, automated teller machines or traffic lights for pedestrian crossings), a lack of sanitation and in limited healthcare facilities ${ }^{1}$. Many small chemicals, even smaller than pathogens, also cause illnesses and fatalities. $\mathrm{NO}_{x}, \mathrm{CO}_{x}$ and particulate arising from the excessive use of fossil fuels, and indoor air pollution caused by volatile organic compounds (VOCs) released from many modern materials lead to numerous health problems ${ }^{2}$.

Despite their ban many decades ago ${ }^{3}$, the intentional release of toxins used as chemical weapons still occurs. Chemical warfare agents (CWAs) are toxic substances that were first used during World War I (WWI) as destructive weapons. In the years following, these weapons were developed into new hazardous substances that we now know as choking agents, blood agents, nerve agents and blister agents. Most of these agents are tasteless and odourless, and, despite being banned, are, unfortunately, still being used in attacks ${ }^{4-6}$. In recent years, great progress has been made in finding ways to handle and destroy CWAs. The Chemical Weapons Convention aims to restrict the misuse of warfare agents by banning the production and stockpiles of chemical weapons by State Parties through the intergovernmental Organisation for the Prohibition of Chemical Weapons (OPCW), which is constantly working on achieving a world free from chemical weapons. For their efforts in this field, the OPCW received the Nobel Peace Prize in 2013.

Unfortunately, the progress made on the development of materials for protective clothing has not kept the same pace as the progress made on the general tools and ways for the destruction of CWAs. Gas masks that were used to protect military and non-military personnel in WWI were made of charcoal filters that work mainly on the adsorption of toxins to prevent their inhalation. However, clogging can affect such filters, making these masks effective only for a few hours ${ }^{7,8}$. Carbon-based systems are still the standard used today, showing the necessity for more advanced protective equipment that not only adsorb but also permanently and selectively degrade toxins. The same can be said for protective clothing, as we elaborate further in the later sections. Currently, these are large chemical-resistant suits with self-contained breathing apparatus that prevent exposure to chemical toxins at the expense of overall mobility. Further progress is needed to design 'smart' materials 
Degradation

The breakdown of a molecule that does not necessarily

render it harmless, as

unselective degradation routes

can produce further toxins.

Antipathogenic

A substance that leads to the neutralization of pathogen

threats

Neutralization

The process by which a

biological or chemical threat

becomes harmless. that not only rely on protection from the threat but also actively degrade the threat and could be incorporated into suits that offer more mobility to the wearer.

Biological warfare attacks have been carried out in many major wars through the last millennium ${ }^{9,10}$, even as far back as the Middle Ages, when corpses were used as catapult ammunition to spread disease in besieged cities $^{11}$. Still, in the current era, bioterrorism is considered a larger threat ${ }^{12}$. Although the (ab)use of biological hazards in warfare is rare compared with the use of chemical weapons, the former poses arguably a larger public risk than chemical pollutants because of their natural abundance in the environment. Viruses and bacteria can spread quickly through populations both locally and internationally, leading to enormous fatality rates. During the West African Ebola outbreak of 2013-2016, more than 10,000 people died and the ongoing cholera outbreak in Yemen has infected over 2 million people and claimed the lives of almost 4,000 as of January 2020 (REF. ${ }^{13}$ ). Internationally, the SARS-CoV-2 outbreak that spread dramatically at the beginning of 2020 has had the most profound effect on communities worldwide in recent times, leading to countries enforcing populations to remain indoors, international travel becoming almost entirely prohibited and worsening economic crises evolving in most countries.

It is vital that, as a global population, we are prepared for the next global biological or chemical threats. Especially those who put themselves in situations of most exposure - doctors, nurses, military personnel and those protecting and caring for the safety of others - should be adequately protected and we should develop environments in which infectious diseases and dangerous chemicals cannot be spread or misused so easily.

Here, we discuss several approaches to achieve a more effective protection against biological or chemical threats. On one hand, we look at the development of coatings for surfaces and functionalized fabrics that will accelerate the inactivation of bacteria and viruses, thus, preventing their spread and, on the other, we explore how to attain a complete degradation of chemical toxins. In the first part of this article, we describe the chemical nature of bacteria and viruses, before investigating mechanisms by which these hazards may be neutralized and the materials that can achieve this. In each case, we look at the progress made towards applying these materials to a functionalized society. We then offer a perspective on how materials scientists, who do not have access to the necessary biological methods to screen for antipathogenic activity, can, instead, use chemical targets as models to predict the activity of new materials. In the second part, we focus on recent advancements in the use of porous catalysts, specifically metal-organic frameworks (MOFs), for the degradation or capture of the most used classes of chemical weapons - nerve agents and blister agents. We highlight the most recent implementations of MOFs on textiles and their uses in the degradation of various CWAs and simulants. We also discuss the applicability and efficiency of these catalysts on textiles in the long term and the challenges they face.

\section{Biological toxins and their remediation}

The National Center for Emerging and Zoonotic Infectious Diseases (NCEZID) divides biological warfare agents (and biological substances in general) into three main categories. Those that fall under category A cause the most damage, as they are highly lethal and toxic, and have the ability to spread widely. However, diseases caused by agents that fall in category B have a lower mortality rate than those caused by category $\mathrm{A}$ agents. As for category $\mathrm{C}$ agents, those are pathogens that can be easily produced in laboratories and have a high rate of infection and death.

Viruses are some of the smallest biological entities, typically in the nanometre size range, and their main components are: genetic material, which can be either RNA or DNA, a protective protein shell surrounding the genetic material, known as a capsid, and, in some cases, a phospholipid coating protecting it all, known as a viral envelope. The viral envelope protects the virus when it is in the environment, waiting to be transferred between hosts. However, phospholipid bilayers are susceptible to attack from surfactants and, therefore, washing hands with soapy water is enough to kill some of the most infectious viruses, such as SARS-CoV-2. Developing materials or coatings that facilitate the destruction of this phospholipid bilayer will, in the future, retard the spread of such infectious viruses through the environment and shared objects. In the absence of the phospholipid envelopes, viable pathways for virus neutralization are offered by inhibiting enzymes, or by the disruption of the capsid proteins or degradation of the genetic material. Bacteria are larger than viruses, typically in the micrometre range, and are prokaryotes - single-celled organisms without membrane-bound organelles, such as a nucleus. Bacterial cells contain genetic information in a single circular chromosome in the cytoplasm within the cell membrane. This cell membrane is typically a phospholipid bilayer and, thus, also bacteria can be neutralized by disrupting this phospholipid membrane.

Despite their different biological risk, viruses and bacteria share similar chemical building blocks and properties. For example, both contain proteins, lipid bilayers and genetic material. It is the chemical bonds within these components that have to be targeted when developing materials and coatings that accelerate the neutralization of the risks in the environment of virus and bacteria. Biological threats do not have simulants in the same way as CWAs; however, for bacteria, several standard strains are typically used. These are easily handled strains with well-established assaying protocols and represent both gram-positive and gram-negative bacteria (that is, in the simplest form, bacteria with a thick cell wall and a thin cell wall, respectively). Such strains are Escherichia coli ${ }^{14}$ and Staphylococcus aureus ${ }^{15}$ for gram-negative and gram-positive bacteria, respectively, but many others are also routinely used. Viruses are often investigated using model viruses, such as bacteriophage P22 $\left(\mathrm{REF}^{16}\right)$ and MS2 $\left(\mathrm{REFS}^{17,18}\right)$; however, they are also investigated more specifically, for example, rotavirus and severe acute respiratory syndrome (SARS) coronavirus ${ }^{19}$ have both been used to test antipathogenic catalytic substrates. 


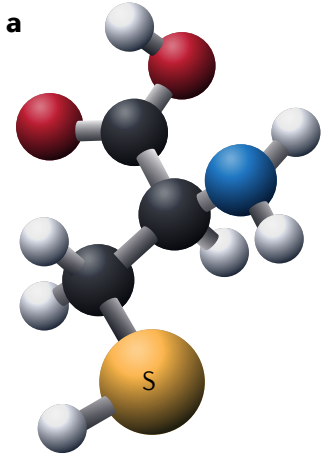

b

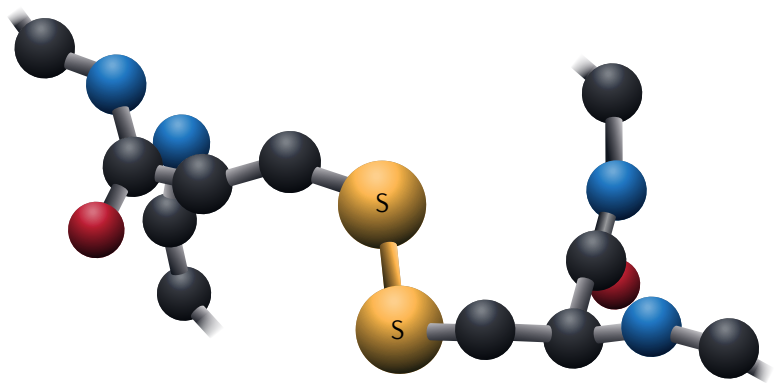

d

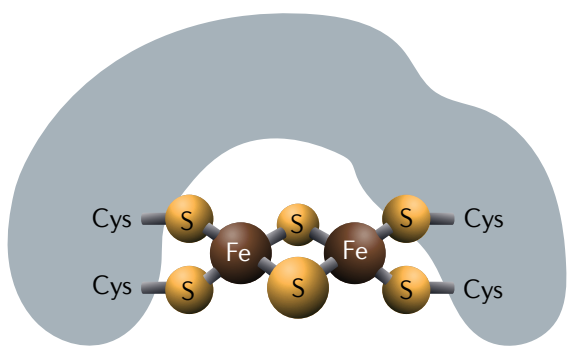

$\mathbf{e}$

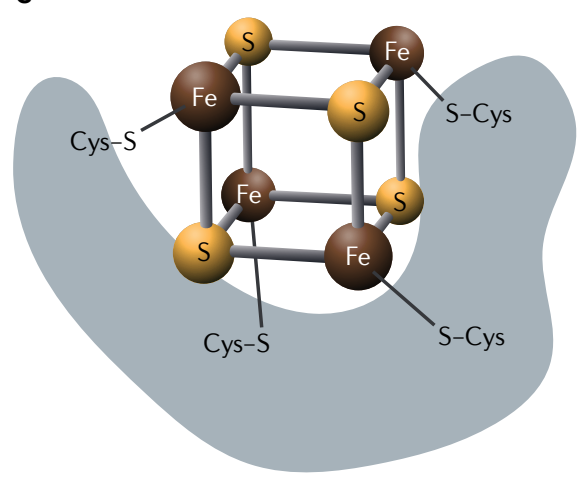

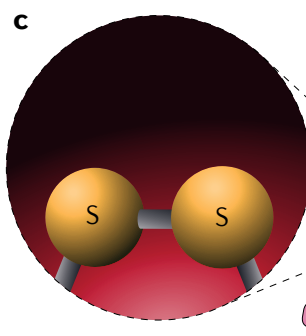

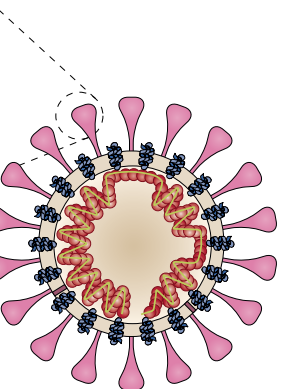

f

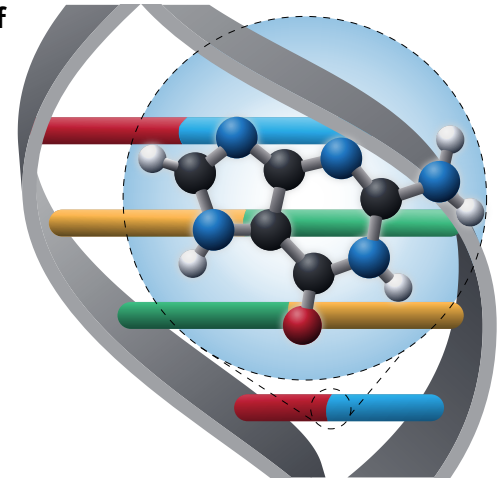

Fig. 1 | Target bonds for antipathogenic activity. a | The amino acid cysteine contains a thiol group that acts as the catalytic site of a number of respiratory enzymes. $\mathbf{b}$ | It also plays a key role in the structure of proteins by forming disulfide bonds. These disulfide bonds also occur in the viral envelope of viruses (panel c), where they are found on the glycoprotein knobs that facilitate binding with host cells. Fe-S clusters (panels $\mathbf{d}$ and $\mathbf{e}$ ) and DNA (panel $\mathbf{f}$ ), in particular, the guanine base, are targets for oxidation.

As mentioned above, bacteria and viruses share some common attributes. By identifying specific chemical moieties that are common sites of attack for antipathogenic catalysts, it may be possible to use small model molecules for the screening of promising materials (FIG. 1). Bacteria - like all other living organisms need to respire, therefore, cell death can be induced by targeting enzymes involved in the respiratory process. The activity of these enzymes is often inhibited by the binding of metal atoms to their active site. One of the most common functional groups that can be targeted in this way is the thiol group (-SH) in enzymes that contain cysteine in the catalytic centre (FIG. 1a). Another target bond, again containing sulfur, is the disulfide bond (R-S-S-R), which results from the oxidation of two thiol groups of cysteine residues. This is one of the most important bonds in proteins (FIG. 1 b), because it enables protein folding and stabilizes their structure. Cleavage of disulfide bonds can denature proteins, leading to cell death. These bonds also appear in glycoproteins in the viral envelope (FIG. 1c), where they mediate the interaction with host cells, therefore, binding to disulfide moieties inhibits viral action. Both of these functional groups can be effectively mimicked in the lab using simple molecules like thiols and disulfides. However, most organic disulfides are symmetrical and those found in nature are asymmetric, thus, care should be taken to make sure that relevant model compounds are used. $\mathrm{Fe}-\mathrm{S}$ clusters are other sulfur-containing targets found in many proteins, therefore, catalysts that can break these Fe-S cages (FIG. 1d,e) cause protein damage that can lead to cell death ${ }^{20}$. These cages could be mimicked in the lab by simple molecules, such as $\mathrm{FeS}_{2}$ but, also, more usefully, by larger biomimetic Fe clusters $^{21}$. Finally, phosphorus-containing bonds are numerous in these biological systems, as they are present in DNA, for example. It has been suggested that, because these are 'soft bases', they can become the target of 'soft acids', such as $\mathrm{Ag}^{+}$that bind to them, and inhibit genetic replication. DNA bases, especially guanine, may be sites of attack through mechanisms such as oxidation (FIG. $1 \mathrm{f}$ ).

\section{Biological toxin degradation with metal nanoparticles} Ag nanoparticles are some of the most commonly used antipathogenic nanomaterials. Their antiseptic properties have been recognized for centuries, with numerous civilizations applying silver to wounds. More recently, $\mathrm{Ag}$ has found application in common plasters to stop infection. Ag is not the only antipathogenic metal; $\mathrm{Cu}$ $\left(\mathrm{REF}^{2}{ }^{22}\right.$ ) and $\mathrm{Zn}\left(\mathrm{REF}^{23}{ }^{23}\right.$ ), among others, have also been well investigated. There are various mechanisms of pathogen neutralization by metals, including oxidative attack through the production of reactive oxygen species (ROS), which is described in further detail in the next section, and metal ion poisoning (FIG. 2a). The latter can occur through numerous mechanisms that involve the binding of metal ions to either pathogen proteins
Death of a cell that, in bacteria equates to death of the organism. 
a

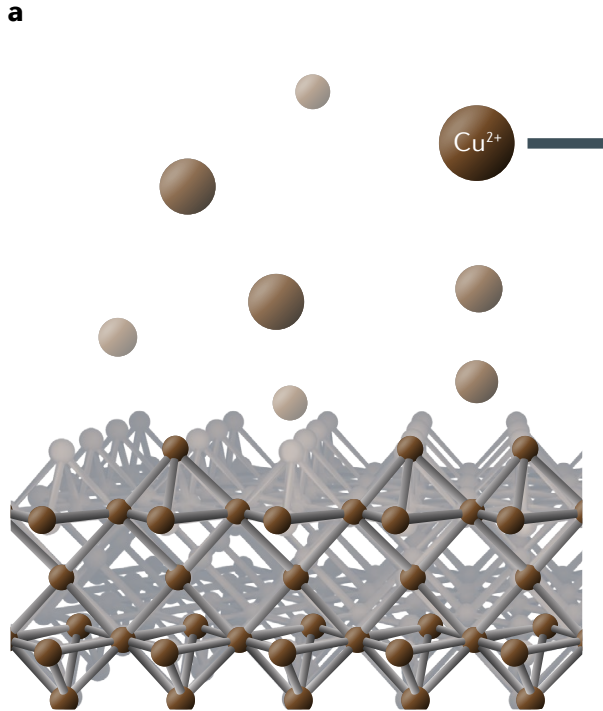

b

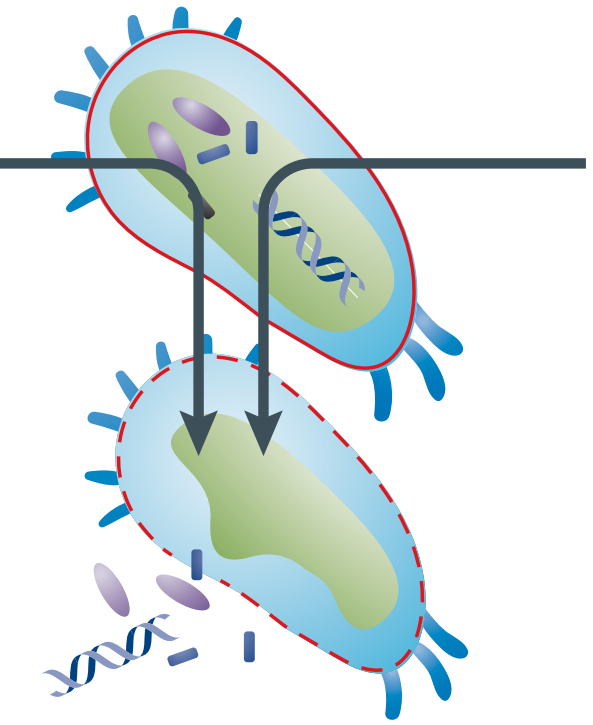

c

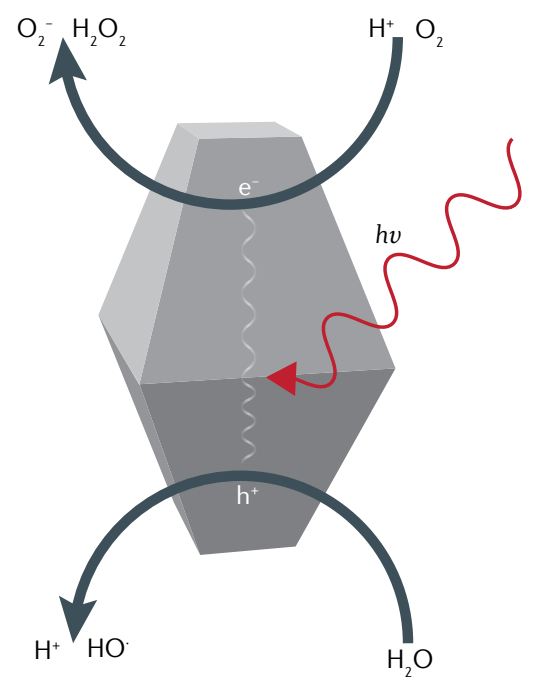

Fig. 2 | Antipathogenic properties of metal-organic frameworks. a | Antipathogenic activity of metal-organic frameworks can originate from the leaching of metal ions, which neutralize pathogens through the breaking of proteins, inhibition of respiratory enzymes and disruption of genetic replication (panel b). c $\mid$ Reactive oxygen species formed by photocatalysts can also neutralize pathogens by causing the rupturing of cell membranes or viral envelopes.

or membranes ${ }^{23}$, binding to genetic material, which prevents replication ${ }^{24}$, or binding to the active site of enzymes ${ }^{23}$.

$\mathrm{Ag}$ and $\mathrm{Cu}$ nanoparticles immobilized on metal-oxide supports have been shown to neutralize viruses, bacteria and fungi ${ }^{25}$. Following the first SARS outbreak in 2003, $\mathrm{Al}_{2} \mathrm{O}_{3}$-supported $\mathrm{Ag}$ and $\mathrm{Cu}$ were investigated for the neutralization of SARS coronavirus, E. coli (bacterium) and Debaryomyces polymorphus (fungus). The study showed that five minutes of exposure to the $\mathrm{Ag}$ nanoparticles inactivated all three pathogens, whereas exposure to $\mathrm{Cu}$ nanoparticles completely inactivated the bacterium and virus and severely, but did not completely, destroyed the fungus. Although the mechanism was not fully investigated, it was suggested to be catalytic oxidation rather than metal poisoning, because $\mathrm{Au}$ and $\mathrm{Cu}$ inactivate bacteria, virus and fungi only under aerobic conditions ${ }^{25}$. The generation of ROS and catalytic oxidation is studied further in the context of photocatalysts in the next section; therefore, the subsequent discussion on the use of metals will focus on the metal ion poisoning mechanism.

Ag nanoparticles have been shown to neutralize both bacteria and viruses through metal ion binding and numerous reports have detailed the effect of nanoparticle size and facet on antipathogenic activity ${ }^{26,27}$. For example, HIV-1 is inactivated only by Ag nanoparticles with sizes in the range of $1-10 \mathrm{~nm}$ that bind to the gp120 receptors, which feature nine disulfide bonds ${ }^{27}$. It has also been speculated that bacteria can absorb $\mathrm{Ag}^{+}$ions from Ag nanoparticles, which can inhibit respiratory enzymes by binding to the $-\mathrm{SH}$ functionality or can neutralize soft bases, such as S and P in DNA bases, as $\mathrm{Ag}^{+}$is a soft acid ${ }^{28,29}$.

MOFs have also been widely researched for antipathogenic purposes. Their modular design with high surface areas, tunable functionalities and incorporation of a number of metal ions make them ideal candidates. MOFs in this field are generally used as metal ion reservoirs, whereby active metal ions $\left(\mathrm{Ag}^{+}, \mathrm{Cu}^{2+}, \mathrm{Zn}^{2+}\right.$ or $\left.\mathrm{Co}^{2+}\right)$ leach from the MOF and neutralize pathogens through catalytic oxidation or metal poisoning. Examples of such MOFs are the popular Cu-containing HKUST-1 (also known as Cu-BTC or MOF-199) ${ }^{30,31}$, Zn-containing BioMIL-5 (REF. ${ }^{32}$ ), several Co-containing imidazolate frameworks (ZIF-67 and Co-SIM-1) ${ }^{33}$ and a Ag-MOF, $\mathrm{Ag}_{3}\left(\mathrm{REF}^{34}\right)$. Although these MOFs work as metal ion reservoirs, antibacterial activity can, in some cases, be attributed to the linkers, as it was reported for a $\mathrm{Zn}-\mathrm{MOF}$ featuring hydrazinebenzoate linkers ${ }^{35}$. A downside of the use of MOFs is that, in order for them to function as antipathogens, their structure needs to be compromised: a release of metal ions (or active linker) leads to the collapse of the structure; therefore, these materials may only be used as temporary antipathogenic surfaces. However, Co-ZIF structures were shown to maintain their antipathogenic properties for three months, meaning that it may be possible to obtain antipathogenic MOF surfaces with long-term activity ${ }^{33}$. The effect of the liberated linker, which, in these tests, is released in solution, has also been investigated for Co-ZIF and Ag-MOFs, and, in all cases, it was shown to have no antibacterial activity ${ }^{33,34,36}$. Recently, a Mn-based MOF, UoB-4, has been shown to exhibit antibacterial properties against both gram-positive and gram-negative bacteria, although the cause of this activity and its mechanism were not investigated ${ }^{37}$.

MOFs have also been used as sensors for the detection of biomarkers for anthrax, an infectious disease caused by Bacillus anthracis. Biomarkers, such as dipicolinic acid (DPA), can be released into solutions by physical or chemical lysis of the bacterial spores and can be used for the identification of anthrax. A luminescent

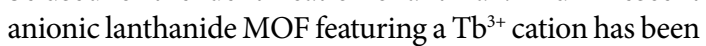


used for the ratiometric luminescence sensing of DPA molecules. The presence of DPA in solution leads to the formation of a Tb-DPA complex, which enhances $\mathrm{Tb}^{3+}$ emission. High selectivity and sensitivity were attained with the Tb-MOF sensor, with a 3.6-nM detection limit. However, this sensor works in solution and is not practical for surface sensing ${ }^{38}$.

A number of MOFs have also been grown onto or incorporated into fibres that provide antipathogenic functionality. Cu-BTC (HKUST-1) MOF has been grown onto synthetic fibres, including polyethylene terephthalate (PET) and nylon, and shown to inactivate three different bacterial pathogens: E. coli, S. aureus and Candida albicans $^{39}$. Importantly, the activity of these MOF-fabric composites showed comparable antipathogenic activity to the commercial MOF powder. One concern that must be addressed is the ecotoxicity of such functionalized fibres, which can be dangerous to other life forms (humans or animals) in the environment. Ecotoxicity was tested by exposing brine shrimp to these MOF-fibres, and no negative effects were observed $^{39}$. HKUST-1 was also used to functionalize cellulose fibres using an aqueous ethanolic solution ${ }^{30}$. The use of ethanol as a solvent is an important step forward, as the preparation of such composites often requires the use of toxic solvents, such as $N, N$-dimethylformamide (DMF). Other MOFs that have been used to prepared MOF-fibre composites include Co-SIM-1, which has been used to functionalize polylactic acid (PLA) fibres through electrospinning ${ }^{40}$.

\section{Biological toxins degradation through ROS}

ROS, such as peroxide $\left(\mathrm{H}_{2} \mathrm{O}_{2}\right)$, superoxide $\left(\mathrm{O}_{2}^{-}\right)$and hydroxyl radicals $\left(\mathrm{OH}^{*}\right)$, react with many biological moieties and can, therefore, be used to neutralize both bacteria and viruses. In this section, we discuss the materials that show promise for ROS generation, the oxidation mechanisms by which these neutralize bacteria and viruses, and how such materials can be modified to provide more desirable properties, before showing how these have been (and can be further) developed into functionalized materials that can be integrated into living and working environments.

$\mathrm{TiO}_{2}$ is one of the best known photocatalysts ${ }^{41,42}$. Upon irradiation with light, ROS are formed through reaction of $\mathrm{O}_{2}$ with electrons or water with holes (FIG. 2C). As previously described, bacteria and viruses account for numerous organic compounds that can be oxidatively attacked by these species, leading to bacterial cell death or virus inactivation. It is widely agreed that the mechanism of bacterial cell death caused by $\mathrm{TiO}_{2}$ photocatalysis begins with the oxidation of the cell membranes by hydroxyl radicals that lead to the disruption of the membrane and subsequent spilling of cytoplasm and genetic material. Further oxidation of these cellular components accelerates the rate of death ${ }^{43,44}$. In the case of membrane-based viruses, (photocatalytic) destruction of this membrane leads to neutralization of the virus particle through virucidal action. ROS can also liberate Fe from Fe-S cages (FIG. 1d,e) that can damage DNA and produce radicals through Fenton reactions, which can, again, damage cell membranes ${ }^{45}$.
Several methods have been investigated to enhance the antipathogenic properties of $\mathrm{TiO}_{2}$ photocatalysts and these usually involve the inclusion of dopants. For example, Ag nanoparticles incorporated within $\mathrm{TiO}_{2}$ films have been shown to increase the virus-inactivation properties of $\mathrm{TiO}_{2}$ photocatalysts ${ }^{46}$. This increase in virucidal activity was mainly attributed to the increased production of $\mathrm{HO}^{*}$, which was confirmed using radical scavengers methanol and $t$-butanol ${ }^{17}$, in addition to contribution from the leaching of active antiviral $\mathrm{Ag}^{+}$ions. This work, consistent with previous literature ${ }^{47}$, also showed that bulk $\mathrm{HO}^{\circ}$ plays a more prominent role than surface $\mathrm{HO}^{*}$ species for virucidal purposes. This is suggested to arise from the unfavourable electrostatic interactions between the tested bacteriophage and surface, leading to repulsion and a lack of surface adsorption ${ }^{47}$. Similarly, it has been shown that $\mathrm{Fe}^{3+}$ ions can enhance the antipathogenic activity of $\mathrm{TiO}_{2}$ up to a certain dopant concentration by acting as electron and hole traps that hinder electron-hole recombination ${ }^{44}$. Pd has also been shown to enhance the virucidal properties of $\mathrm{TiO}_{2}$, with a palladium-modified nitrogen-doped titanium oxide (PdO-TiON) nanofibre demonstrating $>99 \%$ removal of MS2 from solution ${ }^{48} .95 \%$ of the initial concentration was shown to be removed owing to physical adsorption of the virus onto the fibre under dark conditions, and $\sim 95 \%$ of the remaining virus was then removed by the subsequent activity of $\mathrm{HO}^{*}$ formed under visible light illumination.

$\mathrm{TiO}_{2}$-chitosan composites have also been investigated, as these show promising synergistic effects for antipathogenic uses. Chitosan has been widely researched for its antipathogenic properties ${ }^{49}$, especially in the food industry because of its biocompatibility ${ }^{50}$. The polycationic nature of the chitosan surface enables it to bind to the negatively charged cell walls of gram-negative bacteria and it is believed that this increases the permeability of the cell wall, facilitating neutralization ${ }^{51}$. When combined with the photocatalysis by $\mathrm{TiO}_{2}$, the enhancement of bacterial neutralization was observed to be greater than the sum of both individual components ${ }^{52}$. Chitosan- $\mathrm{TiO}_{2}$ composites have also been shown to exhibit enhanced hydrophilicity, which is desirable, as it increases contact between the pathogen and the antipathogenic surface, as well as an increased activation wavelength of the $\mathrm{TiO}_{2}$ into the visible light region ${ }^{53}$.

Finally, $\mathrm{TiO}_{2}$ catalysts must be integrated into functional materials for everyday-life use - powders and thin films that operate in controlled environments are far from being easily applied elsewhere. To this end, these catalysts should be incorporated into fibres that can be used in soft furnishings or as coatings for steel or plastic surfaces. $\mathrm{TiO}_{2}$-fabric composites with cotton and polyester have been reported. Of particular interest is the $\mathrm{TiO}_{2}-\mathrm{PET}$ composite, in which $\mathrm{TiO}_{2}$ is present as anatase nanowires and rutile nanorods ${ }^{54}$. This composite showed excellent antibacterial properties, reaching $100 \%$ sterilization of E. coli and S. epidermidis after $15 \mathrm{~min}$ of visible light irradiation and remarkable antibacterial properties in dark conditions. The antibacterial activity in the dark was attributed to the strain 
of electrostatic adsorption onto the rough anatase surface leading to bacterial death, although a mechanism for such adsorption-stress-induced cell death was not discussed. The visible light activity was attributed to nitrogen doping (introduced during synthesis), which significantly lowered the $\mathrm{TiO}_{2}$ band gap. This fabric composite was also shown to remove VOCs under ultraviolet (UV) irradiation and showed moderate resistance to washing in simulated washing tests.

Photoactive coatings that feature $\mathrm{TiO}_{2}$ have also been prepared using substrates such as glass ${ }^{55}$, tiles ${ }^{56}$ and stee $^{44}$. These coatings have been prepared mainly using sol-gel and dip-coating methods. Photoactive stainless steel is of particular interest because of its role in assisting the spread of the recent SARS-CoV-2 virus. It has been shown that virus particles survive for a number of days on stainless steel surfaces, as opposed to only hours on surfaces such as cardboard or copper ${ }^{57}$; therefore, often-touched street furniture, such as benches or pedestrian crossing buttons, can help facilitate the spread of infection. Coating these objects with a material that inactivates viruses could help reduce the likelihood of future pandemics.

The functionalized materials presented so far show the potential of Ti-based photocatalyst composites for a safer living and working environment. In hospitals, where drug-resistant bacteria and highly infectious viruses pose an enormous threat to those most vulnerable, functionalized steel surfaces and scrubs manufactured from $\mathrm{TiO}_{2}$ composites could help limit the spread by neutralizing these threats before they have the chance to infect. Furthermore, kitchen surfaces made from coated steel and tiles would increase the safety of food preparation, whilst self-cleaning and antibacterial curtains and upholstery would lead to cleaner, higher-quality living areas. However, the mismatch between indoor light spectra and the absorption spectrum of $\mathrm{TiO}_{2}$ urges the development of photocatalyst materials with similar activity but higher absorption of visible light.

Ti-based photocatalysts have also been investigated in the context of MOFs for the inactivation of the SARS-CoV-2 virus $^{58}$. Ti-based MOF, MIL-125(Ti)- $\mathrm{NH}_{2}$, dispersed on stainless steel was shown to inactive the SARS-CoV-2 virus when exposed to UV-C irradiation. An earlier report also highlighted the ability of another Ti-MOF, Ti-TBP, to generate ROS $^{59}$, demonstrating that Ti combined with MOFs can be effective against chemical threats, which are described in depth in the following sections.

\section{Bridging the gap between biological and materials science}

We have discussed two mechanisms for the neutralization of bacteria and viruses: poisoning through metal ions and attack by ROS. By using model compounds or target bonds, new catalysts that can neutralize pathogens through these pathways can be investigated by many research groups, not only by those with the capability for biological screening. For example, ability to degrade $\mathrm{Fe}-\mathrm{S}$ cages, binding affinity with thiols and asymmetric disulfide bond cleavage could all be used as predictors for antipathogenic activity of metal-containing catalysts. ROS generation in desirable environments is the key property for photocatalysts. In this way, materials scientists and chemists can focus on optimizing catalysts and functionalized materials with these desired properties, which can then be tested and used by bioscientists in a collaborative manner. Furthermore, some approaches can be used to tackle both chemical and biological hazards. For example, HKUST-1 is biologically active through poisoning by $\mathrm{Cu}^{2+}$ ions and can also degrade chemical hazards posed by organophosphates. ROS have been shown to oxidize many organic pollutants, such as VOCs and warfare agents, like sulfur mustard. A cotton-based fabric functionalized with a $\beta$-cyclodextrin polymer was shown to capture organic contaminants from air and water ${ }^{60}$. Despite the narrow window of individual research topics, the materials used have a broad spectrum of applications and, already, the introduction of a couple of these into smart materials would lead to a safer society. Finally, it is worth noting that these products are already available, demonstrating that these ideas are already becoming a reality. The idea of using conventional textile materials for environmental purposes has inspired the product developers at IKEA to design indoor air-purifying curtains that reduce indoor air pollutants ${ }^{61}$ by using mineral-based photocatalysts that are activated by natural light. Similarly, sportswear companies are starting to use similar catalysts to keep clothes odour-free and fresh.

\section{Chemical toxins and their remediation Chemical toxin degradation using MOFs}

MOFs are capturing the prime focus of many researchers for the detoxification of CWAs and their simulants ${ }^{62}$. They offer a promising platform because of their vast tunability: the different combinations of metal clusters and organic ligands allow these materials to be tuned depending on the application ${ }^{63}$. Many recent reviews have been devoted to the activity of MOFs against toxic chemicals in general, including an in-depth description on their role as CWA catalysts ${ }^{64-66}$.

Several catalysts with high activity and selectivity for the adsorption and/or detoxification of these toxic agents have been explored and, yet, the rate of detoxification remains a big challenge. Even though academic research is limited by the danger of conducting experiments with actual agents, simulants are being exploited, instead of actual toxins, in many studies to safely but accurately mimic the reactivity of these agents. These simulants are chosen to match the structure of the original agent as much as possible. However, because the behaviour of simulants is not always representative of the real agent and because of the lethal properties of CWAs, certified laboratories with adequate facilities and personnel are needed to validate such studies ${ }^{67-69}$.

Nerve agents and their simulants. Organophosphatebased CWAs, when inhaled or come into contact with the skin, poison the nervous system, hence, they are referred to as nerve agents, and are known to be the most lethal of the classic CWAs, having the ability to be fatal within a few minutes ${ }^{70}$. Nerve agents operate 
Nerve agents<smiles>CC(C)O[P+](C)=O</smiles>

GB<smiles></smiles>

$\mathrm{GD}$
Nerve a

MPA

$$
\text { DMMP }
$$

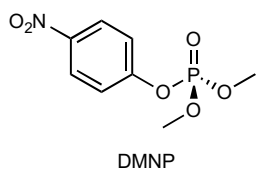

b V agent (VX)

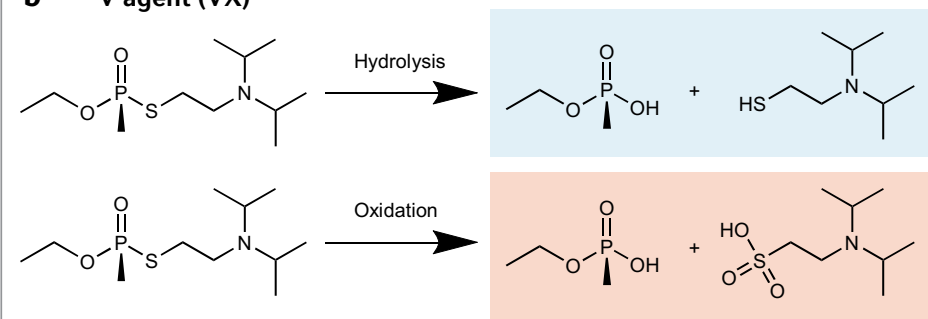

G agent (GD)

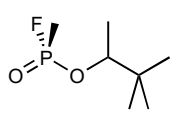

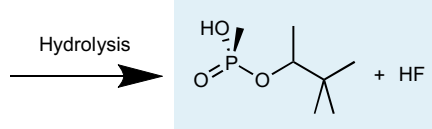

Fig. 3 | Degradation pathways of nerve agent simulants. a | Molecular structure of some nerve agents (left) and their simulants (right). $\mathbf{b} \mid$ An example of the hydrolysis and oxidation pathways of $\mathrm{V}$ agent venomous agent $\mathrm{X}(\mathrm{VX})$ and the hydrolysis products of G agent soman (GD). DMMP, dimethyl methylphosphonate; DMNP, dimethyl p-nitrophenylphosphate; GA, tabun; GB, sarin; MPA, methylphosphonic acid.

by inhibiting the acetylcholinesterase enzyme, which breaks down the neurotransmitter acetylcholine, leading to asphyxiation caused by the hindrance of muscle contractions ${ }^{71}$. G-series nerve agents, such as tabun $(\mathrm{GA})$, sarin $(\mathrm{GB})$ and soman $(\mathrm{GD})$, are more volatile than $\mathrm{V}$-series agents, mainly venomous agent $\mathrm{X}$ (VX). The latter is considered the most lethal of CWAs ${ }^{72}$. The detoxification of nerve agents can be realized through either hydrolysis or oxidation ${ }^{73}$. Some research groups have been able to hydrolyse nerve agents and their simulants with MOFs through bioinspired catalytic routes. However, nerve agents are preferably detoxified through oxidation because their breakdown through hydrolysis results in the formation of more toxic products. Hence, each degradation pathway will depend on the type of nerve agent and is limited by the toxicity of some of the intermediates and final products formed during degradation ${ }^{73}$. Nerve agent simulants such as dimethyl methylphosphonate (DMMP), which retains similar volatility and polarity properties as sarin, and dimethyl $p$-nitrophenylphosphate (DMNP) are mainly used experimentally, because they are safer to handle. However, reported values of tested simulants are often inimitable when tested on actual CWA agents, and additional modifications are often required, owing to unsimilar behaviour of the actual nerve agent to the simulant. An overview of the degradation pathways of simulants of V-series and G-series nerve agents can be found in FIG. 3 .

The first MOFs investigated for the detoxification of CWAs have been $\mathrm{Zn}-\mathrm{MOF}^{74}$ and Al-MOF${ }^{75}$. More recent studies have focused on $\mathrm{Zr}(\mathrm{Iv})$-based MOFs for the hydrolysis of nerve agents and their simulants, as these were found to be highly stable at elevated temperatures and at different $\mathrm{pH}$ values ${ }^{65,76-78}$. The hydrolysis reaction is driven by the $\mathrm{Zr}(\mathrm{Iv})$ metal node centres that act as strong Lewis acid sites ${ }^{79}$. The two-step reaction mechanism first involves the nucleophilic addition of $\mathrm{OH}$ groups to the nerve agent, which are coordinated to a $\mathrm{Zr}$ metal centre of the MOF. This will lead to the formation of a penta-coordinated phosphorus intermediate. The final product, phosphonic acid, is then obtained through an elimination step, which also produces hydrofluoric acid or isopropanol as final products ${ }^{80}$.
Zr-based UiO-66 was the first system to be investigated for the hydrolysis of the phosphate-based nerve agent simulant $\mathrm{DMNP}^{81}$. The combination of strong Lewis-acidic $\mathrm{Zr}(\mathrm{IV})$ and bridging hydroxide anions in UiO-66 led to the active and selective hydrolysis of DMNP, with an approximate half-life $\left(t_{1 / 2}\right)$ of $45 \mathrm{~min}$. Following studies revealed that $t_{1 / 2}$ for the DMNP hydrolysis could be decreased by a factor of 10 when UiO-67 was used in place of UiO-66. UiO-67 has larger pores compared with $\mathrm{UiO}-66$ because of the extended length of its linker ${ }^{82}$. Such minor modification in the catalyst shows the vast improvement in DMNP hydrolysis, giving rise to promising application in the fast degradation of such toxins. This shows that catalyst modification is important and unique to every application. Similarly, Zr-based MOF-808, UiO-66 and UiO66- $\mathrm{NH}_{2}$ have been shown to be excellent candidates for the decomposition of nerve agents, even under high relative humidity ${ }^{83}$. Building on their previous findings ${ }^{84}$, de Koning and co-workers have also recently designed a detection kit for VX-contaminated surfaces, which uses a combination of the Zr-based NU-1000 MOF and 5,5'-dithiobis-(2-nitrobenzoic acid) (DTNB) ${ }^{85}$.

Realistically, chemical attacks occur in dry or humid conditions, and toxic substances are released in the gas phase instead of buffered solutions, thus, experimental conditions should be adjusted accordingly when studying the detoxifications of CWAs. Also, the chemical weapon deployed is often unknown and deadly, hence, the need to quickly detoxify and identify the toxin is essential in order to control its dispersion and properly treat it if exposed to humans. Dual-function catalysts are ideal in such situations and they will be further discussed is the coming sections.

Blister agents and their simulants. Also known as vesicant agents, blister agents were first used during the WWI as a chemical warfare weapon. Upon contact with the skin, eyes, lungs or any other mucous membrane, chemical burns such as large blisters filled with fluid will form on the exposed area. These agents fall under three major categories: sulfur mustard (HD), also known as mustard gas and nitrogen mustard (HN-1,2,3), phosgene oxime (CX) 
and lewisite (L) ${ }^{72}$. In the Iran-Iraq war (1980-1988), HD was used as a chemical weapon. As a result, more than 100,000 poorly protected people suffered from severe injuries and about one-third continued to suffer longlasting consequences after exposure ${ }^{86}$. Sulfur mustard acts as an alkylating agent by stopping protein synthesis in the body through the inhibition of the transcription of DNA into RNA. These toxins are characterized by their yellowish colour and strong odour, and are often released through bombs, explosives, rockets or spray tanks. Even though blister agents are less vigorous than nerve agents, signs of injury may not directly appear after exposure. It might take several hours and sometimes days, depending on the exposure concentration ${ }^{87}$.

An extensive amount of research has been done on the capture or degradation of mustard gas. Catalytic HD detoxification through hydrolysis is one of the proposed approaches. However, this can be limited by the formation of toxic by-products, such as $\mathrm{HCl}$, that inhibit the catalyst during degradation. Such a restraint may lead to incomplete degradation of HD and the formation of dangerous side products. Furthermore, the surface of HD droplets can be coated by products formed during hydrolysis, leading to a delay in further HD dissolution ${ }^{87}$.

A more promising route is the oxidation of $\mathrm{HD}$ to sulfoxide. However, a selective oxidation is needed to control the formation of undesired products. The over-oxidation of HD (FIG. 4) leads to the formation of bis(2-chloroethyl) sulfoxide (SO), which bears one oxygen and is considered benign, and bis(2-chloroethyl) sulfone $\left(\mathrm{SO}_{2}\right)$, which has similar blistering properties as mustard gas ${ }^{88}$. Effective simulants for HD are 2-chloroethyl ethyl sulfide (CEES), 2-chloroethyl ethyl ether (CEEE) and 2-chloroethylphenyl sulfide (CEPS) ${ }^{89}$. These simulants have been used in many preliminary experimental studies for security reasons and usage restrictions of the HD agent ${ }^{90}$.

Nanoporphyrin-based MOFs (Por-MOFs), combined with blue light-emitting diode (LED) irradiation, were used to selectively decompose the HD simulant

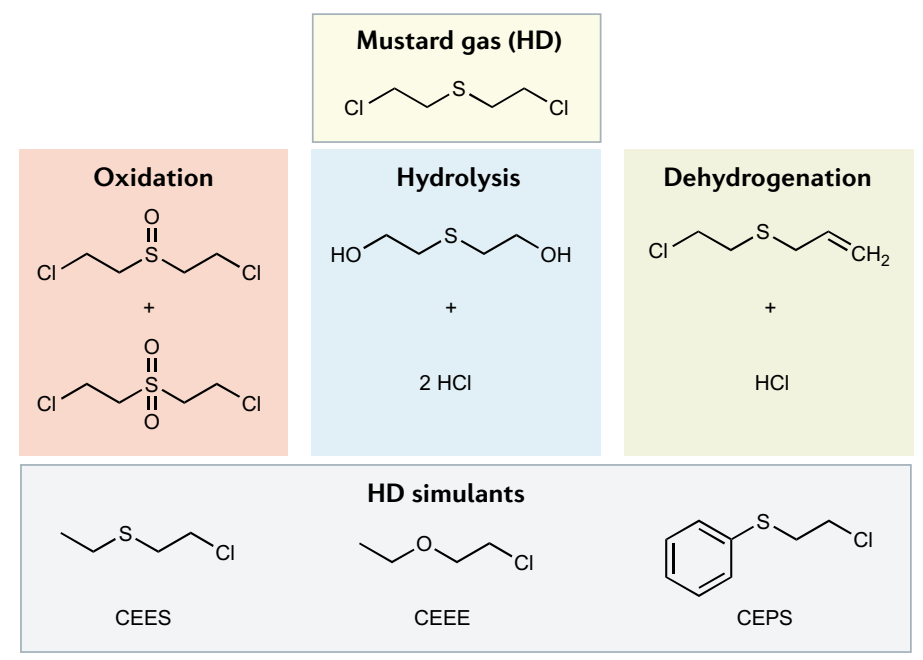

Fig. 4 | Mustard gas and its simulants. The different catalytic degradation pathways of sulfur mustard (HD) and the molecular structure of some HD simulants. CEEE, 2-chloroethyl ethyl ether; CEES, 2-chloroethyl ethyl sulfide; CEPS, 2-chloroethylphenyl sulfide.
CEES to non-toxic products, such as 2-chloroethyl ethyl sulfoxide (CEESO), without the formation of $\mathrm{CEESO}_{2}$ (REF. ${ }^{91}$ ). The catalyst was dispersed in methanol and the solution was purged with oxygen for $20 \mathrm{~min}$. CEES was then added using a micro syringe. The detoxification half-life of CEES was $14 \mathrm{~min}$. Even though this photo-oxidation reaction was a success, one should keep in mind that HD is less soluble in methanol compared with CEES. Hydrophobic MOFs are preferred for capturing hydrophobic sulfur mustard and its simulants. However, ideally speaking, an amphiphilic catalyst is preferred, as these chemicals are used in dry as well as humid conditions.

\section{Chemical toxins degradation by dual-function MOFs}

Bifunctional MOFs for the detoxification of chemical toxins are ideal when the type of chemical attack is unknown, which is often the case. Because different agents react differently to the same degradation route, improvements have been made in designing dual-function catalysts that can simultaneously detoxify nerve agents and blister agents. Dual-function MOF catalysts have been explored on CWA simulants.

Nanoporphyrin-based Zr(IV)-MOFs were used for the simultaneous detoxification of nerve agent simulant DMNP and mustard gas simulant CEES at room temperature $^{92}$ (FIG. 5). The degradation of the simulants occurred under visible (blue LED) irradiation through the simultaneous hydrolysis of DMNP and oxidation of CEES ( $t_{1 / 2}$ of 8 and $12 \mathrm{~min}$, respectively). This versatile MOF features $\mathrm{Zr}_{6}$ nodes combined with photoactive porphyrin linkers. Such structure enables a phosphotriesterase-like activity, which is fundamental for the hydrolysis of organophosphate, and the photoactive porphyrin linkers enable the oxidation of sulfur-containing substances. Such a system is useful for CWA spills or detoxification of stockpiles, but it is inconvenient for fast on-site detoxification.

Ten different Zr-based MOFs with distinct surface area to pore volume ratio, secondary building unit connectivity and open metal sites have been used to investigate the influence of topology on the capture and degradation rate of $\mathrm{GB}$, a nerve agent simulant, and CEES, a blister agent simulant ${ }^{93}$. Breakthrough experiments and dose-extraction tests were compared for all ten MOFs. The results show that higher loadings of GB and CEES were obtained for catalysts with the largest surface areas and pore volumes. This can be explained by the facile diffusion of the molecule into the MOF. In humid conditions, water molecules interact with the active site, leading to fewer available active sites for CEES to bind to the secondary building unit. In both humid and dry conditions, NU-1000 showed the lowest desorption amount of CEES. The micropores of UiO-66 may have limited the diffusion of GB, which led to a smaller desorption percentage. Such a study shows that some MOFs are ideal for decontamination purposes, while others fit best filtration applications. Therefore, a careful selection of linker or node functionalization can help to effectively capture hydrophobic molecules, such as CEES, and simultaneously hydrolyse nerve agents (which requires water). 


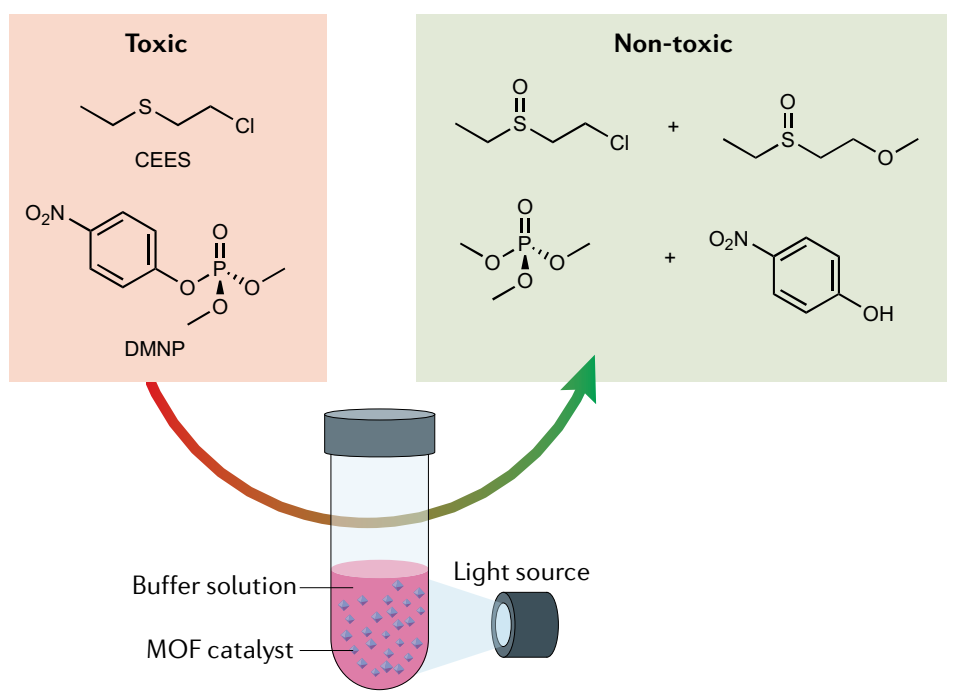

Fig. 5 | Dual transformation of chemical toxins. The dual transformation of chemical warfare agent simulants (red) 2-chloroethyl ethyl sulfide (CEES) and dimethyl p-nitrophenylphosphate (DMNP) to non-toxic oxidative and hydrolytic products, respectively (green), through a MOF-catalyzed dual reaction. The degradation of CEES and DMNP occurs under visible irradiation (light source) through the simultaneous hydrolysis of DMNP and oxidation of CEES. MOF, metal-organic framework.

As has been discussed thus far, MOFs offer an incredibly cheap, versatile and active solution to degrade or adsorb CWAs. However, there is a huge gap between showing their activity in a test tube or in a small-scale lab experiment versus taking them into a war zone for active use. For the latter application, the powder-form MOF crystals are far from ideal and they must be adapted to be suitable for any desired application. The following section summarizes the most recent development in the application of MOFs on textiles for actual use in war zones.

\section{Chemical toxins degradation by textile-MOF composites}

We previously mentioned the examples that prove the concept of textiles as detoxication materials, such as indoor air-purifying curtains. Similar studies have been conducted on CWA simulants and have shown that catalysts integrated into fabric are more effective than their isolated powder form ${ }^{94}$. These results have been corroborated by the study of Al-porphyrin-based MOF (Al-PMOF) powder and Al-PMOF integrated into polypropylene (PP) fibre composite (PP@Al-PMOF) for the photo-oxidation of CEES under $\mathrm{O}_{2}$ and LED irradiation. MOFs' linkers containing photosensitive groups were used to achieve a fast degradation of CEES, with $t_{1 / 2}$ of 16 and $4 \mathrm{~min}$ for the powder form and PP@AlPMOF, respectively ${ }^{94}$. CEES was degraded only under irradiation, which indicates that such technology could be promising if integrated in everyday textiles for the detoxification of the surrounding environment from CWAs. The concept behind such applications should be incorporated on other textiles, such as clothes for personal protective equipment (PPE), hospital blankets, multipurpose cleaning wipes and so on, to limit primary and prevent secondary exposures to toxic chemicals and pollutants. More relevant examples and recent studies on the use of MOFs on textiles for the detoxification of CWAs are discussed in the following sections. It is worth mentioning that the detoxification during an attack may need to be handled differently in different circumstances, and light-activated degradation may not always be the preferred protection route.

It has traditionally been difficult to bridge the gap between potential interesting applications of MOFs and their actual use, often because of their poor thermal stability or uncertain stability in aqueous environments. However, we want to stress that this is not the case for all MOFs and that these materials should not be discarded too easily. In the following section, we set out to discuss how these materials can also be manipulated and applied in different ways to suit the numerous applications in CWA degradation. We do this by discussing also the unique challenges presented by CWA degradation in different situations. Treating a barrel of CWA found in a stockpile is very different than safeguarding against the same molecule when airborne during an attack. As such, we look at three broad scenarios: destruction of stockpiles, protection in the event of an attack and decontamination of land and surfaces after an attack. In the context of each of these situations, we discuss how MOFs have been applied to tackle these situations, how this can be built upon in the future and their unique challenges.

Destruction of stockpiles of chemical toxins. As of 31st December 2019, the OPCW states that 193 countries (accounting for $98 \%$ of the world's population) are committed to the Chemical Weapons Convention and that $97 \%$ of chemical weapons stockpiles declared by these countries have been verifiably destroyed. That is over 70,000 metric tons of chemical agents destroyed with a little over 2,000 metric tons yet to be destroyed. Despite their abundance, the destruction of stockpiles probably presents the least amount of challenge. Although much progress has been made in their destruction, research is ongoing to find safer and more efficient ways to render them unusable. One such method is the use of MOF-loaded cellulose sponges for the degradation of a nerve agent simulant ${ }^{95}$. In this case, UiO-66- $\mathrm{NH}_{2}$ was synthesized onto a highly porous cellulose sponge through chemical crosslink of the powder form of the MOF. The detoxification of DMNP was relatively fast, with $t_{1 / 2}<9 \mathrm{~min}$. Despite these promising results, nerve agent simulants do not always behave similarly to the actual agent. Therefore, a more recent technique has been proposed in which a Zr-based MOF immobilized on a sponge was used for stockpile degradation ${ }^{96}$. This functionalized material facilitates the rapid neutralization of VX barrels through immobilization of the agent, followed by hydrolysis. A $0.68 \mathrm{~mol} \%$ loading of MOF-808 (relative to VX) was shown to degrade VX in the presence of water, with $t_{1 / 2}<1 \mathrm{~h}$. This approach seems to be promising for bulk absorption and will definitely ease the decontamination process of CWA stockpiles and spills.

Despite an estimated $97 \%$ of stockpiles being destroyed, chemical weapons attacks are still a threat and continue to be used despite their prohibition, taking countless 
a

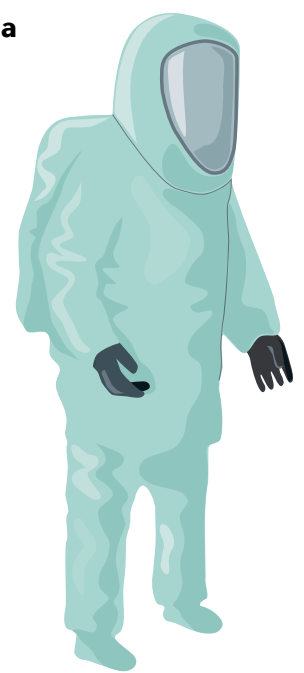

b

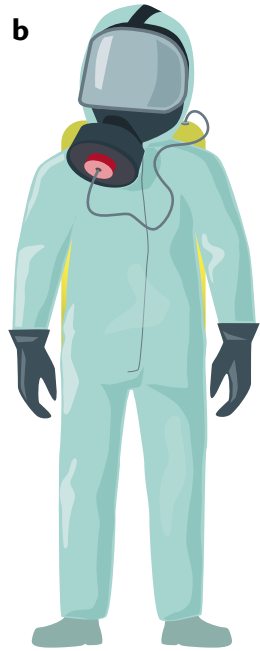

C

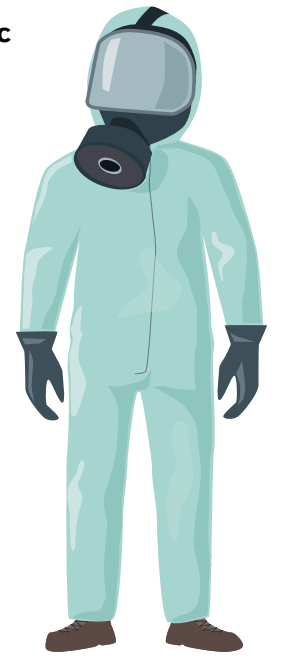

d

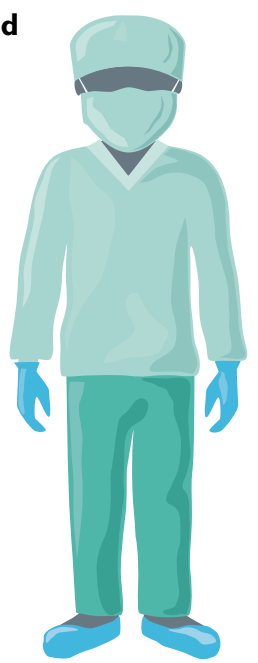

Fig. 6 | The four different types of personal protective equipment categories. Classified by the US Environmental Protection Agency (EPA). a | Suit used to protect from unknown agents that offers maximal protection. $\mathbf{b} \mid$ Suit used for high respiratory protection that does not offer complete skin protection. $\mathbf{c} \mid$ A splash suit that features an air-purifying respirator. $\mathbf{d}$ | The common work uniform used by medical personnel.

lives. Therefore, it is paramount that, as well as using MOFs to destroy stockpiles, we find applications that can protect those most vulnerable to attack.

Functionalized protective clothing against attacks with chemical toxins. The US Environmental Protection Agency (EPA) classifies PPE in four different levels ${ }^{97}$ (FIG. 6). Level A PPE is mainly used to protect from unknown agents and offers maximal protection. This includes a self-contained breathing apparatus and a chemical-resistant suit. Level B PPE is used when the agent poses high respiratory risks and not as much skin protection is needed. A splash suit is used as level C PPE for the same skin protection level as in B, but an airpurifying respirator is used instead of a self-contained breathing apparatus. Level D is the common work uniform used by medical personnel.

MOFs have been widely used in various forms of PPE, including masks, membranes and fabrics ${ }^{98}$. Furthermore, two types of MOF-functionalized fabrics have been explored: those that chemically degrade the CWA and those that merely stop contact, either by adsorption or repulsion ${ }^{94,99-104}$. Most desirable is a fabric that can both absorb and degrade CWAs in a suitable timescale. Materials that simply repel or shed the CWA are the less desirable because of the persistence of CWAs in the environment, which we discuss in more detail later.

A process for the decontamination of military nerve and blister agents was patented by Cowsar and colleagues in 1988. The process involves the oxidation of these agents to non-toxic products with gaseous ozone or chlorine dioxide through direct contact of the contaminated items, such as clothing. The decontamination takes a few minutes and does not affect the quality or the composition of the fabric ${ }^{98}$. However, several ways have later emerged to detoxify toxins from textiles ${ }^{94,99-104}$. The application of MOFs to create PPE with the aim to degrade CWAs has mainly focused on the UiO-66 family (including $\mathrm{UiO}-67$ and $\mathrm{UiO}-66-\mathrm{NH}_{2}$ ) discussed earlier and attempts to incorporate these into fabrics and membranes to create functionalized protective clothing to withstand chemical attack. There have been numerous methods by which MOFs have been introduced into fibres or fabrics, including electrospinning, atomic layer deposition combined with solvothermal preparation and post-synthetic polymerization (PSP). Illustrations of these, examples of the materials that can be prepared and their catalytic performance compared with regular fabrics are shown in FIG. 7. For an in-depth summary of these methods and their use, we direct the interested reader to recent, comprehensive reviews by Phadatare and Kandasubramanian ${ }^{99}$ and $\mathrm{Ma}$ and co-workers ${ }^{100}$. A MOF-fabric composite is prepared by first depositing a layer of metal oxide on the fibre using atomic layer deposition, followed by MOF growth using solvothermal methods (FIG. 7a). This approach has been used to grow $\mathrm{PMOF}$ on an $\mathrm{Al}_{2} \mathrm{O}_{3}$ layer deposited on $\mathrm{PP}^{94}$ and to grow $\mathrm{UiO}-67$ on $\mathrm{a} \mathrm{TiO}_{2}$ layer deposited on polyamide- 6 $(\mathrm{PA}-6)^{101}$ (FIG. 7b). PP itself has no activity towards CWAs (FIG. 7C). However when prepared as a composite fibre with $\mathrm{Al}_{2} \mathrm{O}_{3}$ and PMOF, it selectively converts $100 \%$ of the sulfur mustard simulant CEES to the non-toxic CEESO within 20 mins. The same DMNP hydrolysis rates were reported for UiO-67 in the PA-6@TiO @UiO-67 composite and $\mathrm{UiO}-67$ in powder form (FIG.7d).

Fast protection was also observed by spray coating a MOF-polymer hybrid catalyst onto a nylon and cotton blended fibre (Nyco fibre) ${ }^{102}$. However, this technique can only be applied to amine-terminated polymers through PSP that leads to the formation of a thiourea bond, thus, resulting in UiO-66-isothiocyanate polythiourea (UiO-66-NCS-PTU) (FIG. 7e,f). Although the catalytic activity of this MOF-fibre composite was maintained, the hydrolysis rate of DMNP through thiourea MOF was four times slower compared with UiO-66-NCS ${ }^{102}$ (FIG. 7g). 
Electrospinning is another approach for the preparation of MOF-fibre composites, by which an electrical charge is used to draw polymer droplets into fibres (FIG. 7h). This approach was used to prepare a UiO-66$\mathrm{NH}_{2}$ matrix with polyvinylidene fluoride (PVDF), dubbing the resultant fabric MOFabric ${ }^{105}$. This fabric was tested for the degradation of both DMNP (VX simulant) and GD. Although MOFabric was active for the degradation of DMNP and its activity scaled with MOF loading, none of the composites were as active as the powder
MOF. This was attributed to the clustering of crystals on the composite and illustrates one of the great challenges in functionalizing such MOFs, namely, the limited diffusion of the agent within the pores of the MOF-fibre composite. Remarkably, when MOFabric was tested for GD degradation, the composite with higher loadings of MOF $\left(19-33 \%, t_{1 / 2}=161-131 \mathrm{~min}\right)$ resulted in being more active than the powdered MOF $\left(t_{1 / 2}=315 \mathrm{~min}\right)$. This was attributed to the low surface energy of PVDF that aids dispersibility of GD through the fibre. These promising a

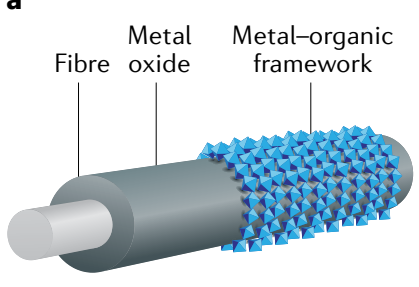

b

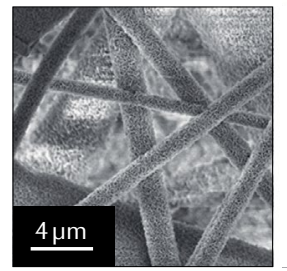

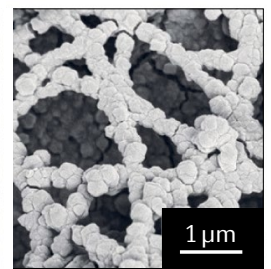

c

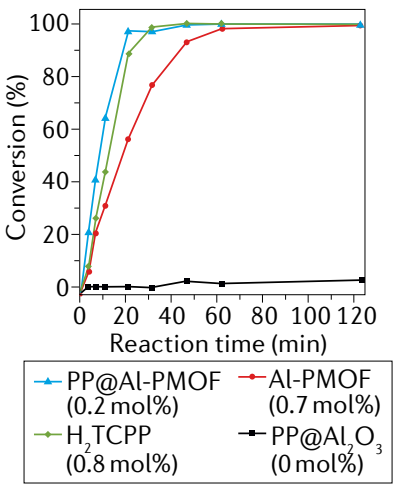

d

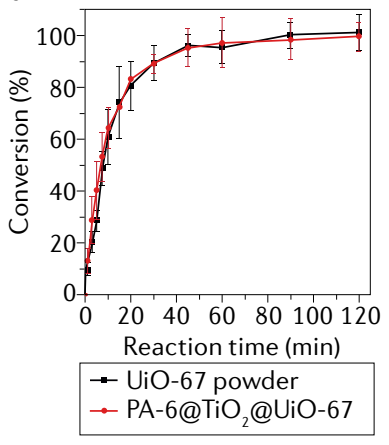

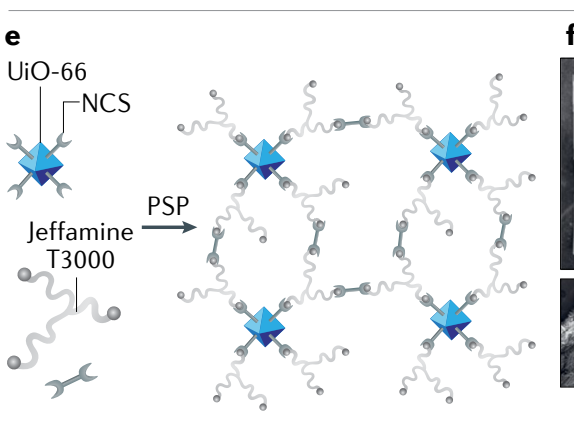
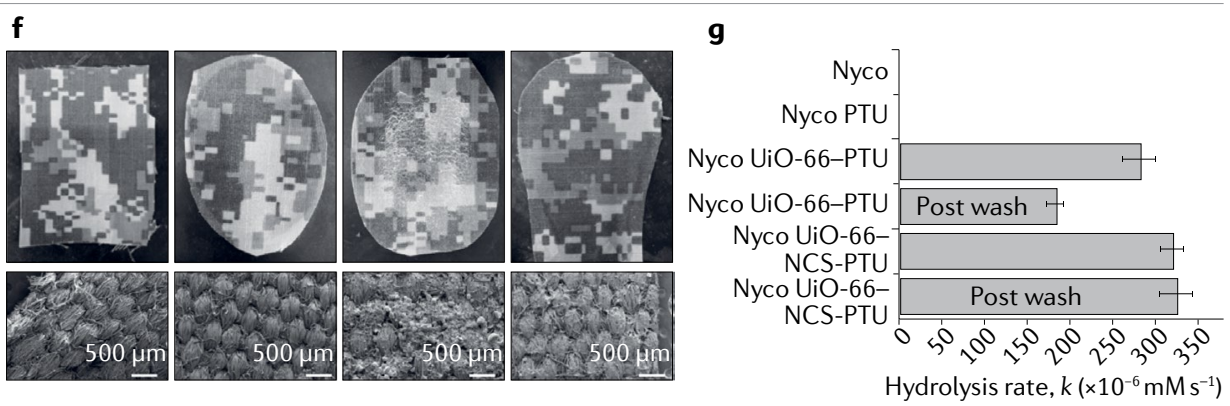

h

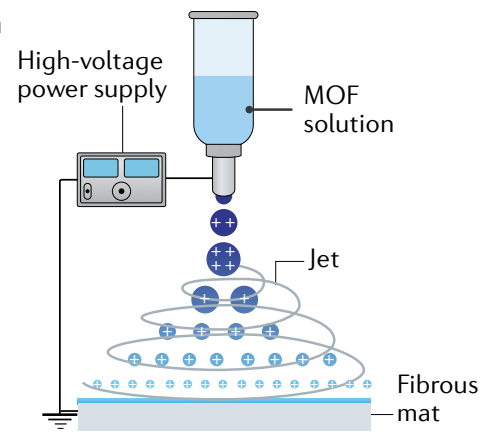

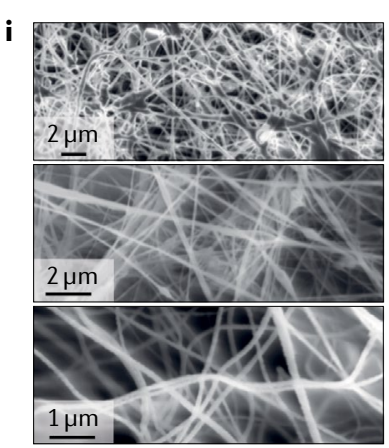
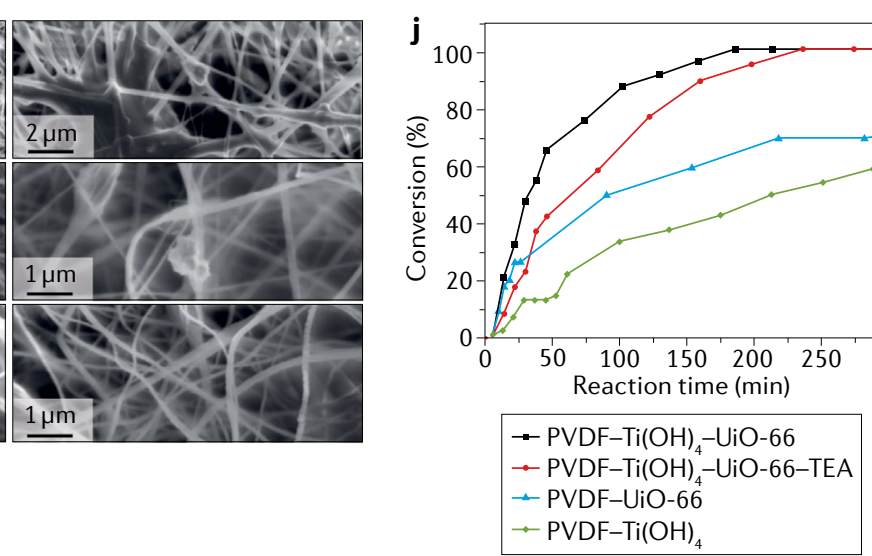

Fig. 7 | Methods of incorporating metal-organic frameworks into fabric. Three different techniques are used to functionalize fibres with metalorganic frameworks (MOFs): atomic layer deposition (ALD), post-synthetic polymerization (PSP) and electrospinning. a |ALD. $\mathbf{b} \mid$ Scanning electron microscope (SEM) images of Al-based polypropylene-MOF ${ }^{94}$ (left) and Ti-based MOF, polyamide (PA)-6@TiO,@UiO-67 (REF. ${ }^{101}$ ) (right) obtained through ALD. c | Oxidation profiles of 2-chloroethyl ethyl sulfide (CEES) to 2-chloroethyl ethyl sulfoxide (CEESO) - conversion over time - using various photocatalysts ${ }^{94}$. $\mathbf{d}$ |Conversion of dimethyl $p$-nitrophenylphosphate (DMNP) versus reaction time using MOF powder and MOF-fabric ${ }^{101}$.e $\mid$ PSP. f | Top: optical images of swatches of Nyco fibres (left to right): pure Nyco, polythiourea (PTU) on Nyco, UiO-66-PTU on Nyco and UiO-66-NCS-PTU on Nyco. Bottom: corresponding SEM images ${ }^{102}$.g | DMNP hydrolysis rates before and after conducting the laundry wash simulation ${ }^{102}$. h | Electrospinning. i | SEM images of polyvinylidene fluoride (PVDF)$\mathrm{Ti}(\mathrm{OH})_{4}-\mathrm{UiO}-66$-triethanolamine (TEA) (top left and right), PVDF- $\mathrm{Ti}(\mathrm{OH})_{4}-$ UiO-66 (middle left and right) and PVDF-Ti $(\mathrm{OH})_{4}$ (bottom left and right) ${ }^{103}$. j | Conversion of soman with PVDF composite samples ${ }^{103}$. NCS, isothiocyanate; PMOF, porphyrin-based MOF. Parts $\mathbf{b}$ (left) and $\mathbf{c}$ adapted with permission from REF. ${ }^{94}$, Elsevier. Parts $\mathbf{b}$ (right) and $\mathbf{d}$ adapted with permission from REF. ${ }^{101}$, Wiley. Parts $\mathbf{f}$ and $\mathbf{g}$ adapted with permission from REF. ${ }^{102}$, Wiley. Parts $\mathbf{i}$ and $\mathbf{j}$ adapted with permission from REF. ${ }^{103}$, ACS. 

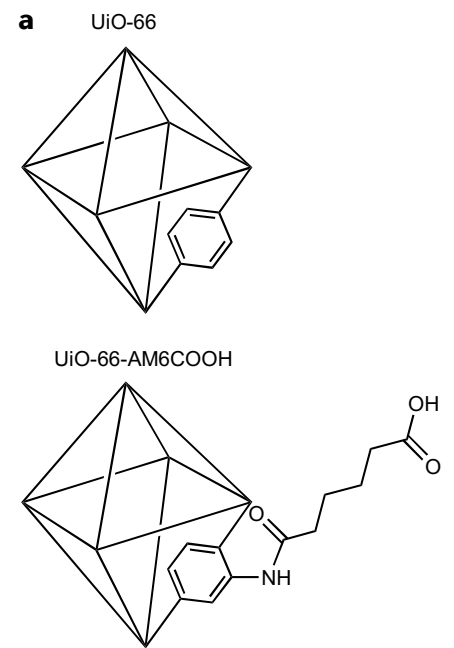
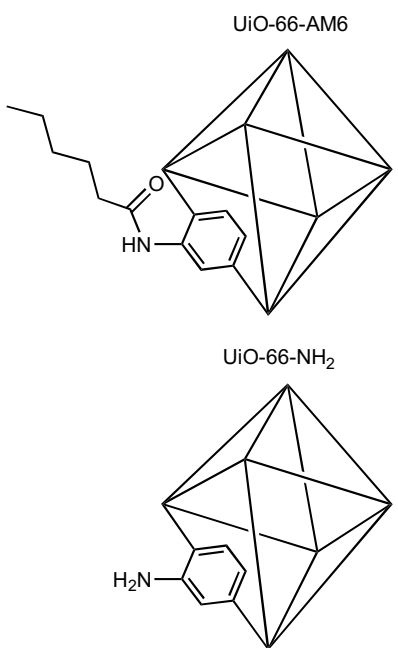

b

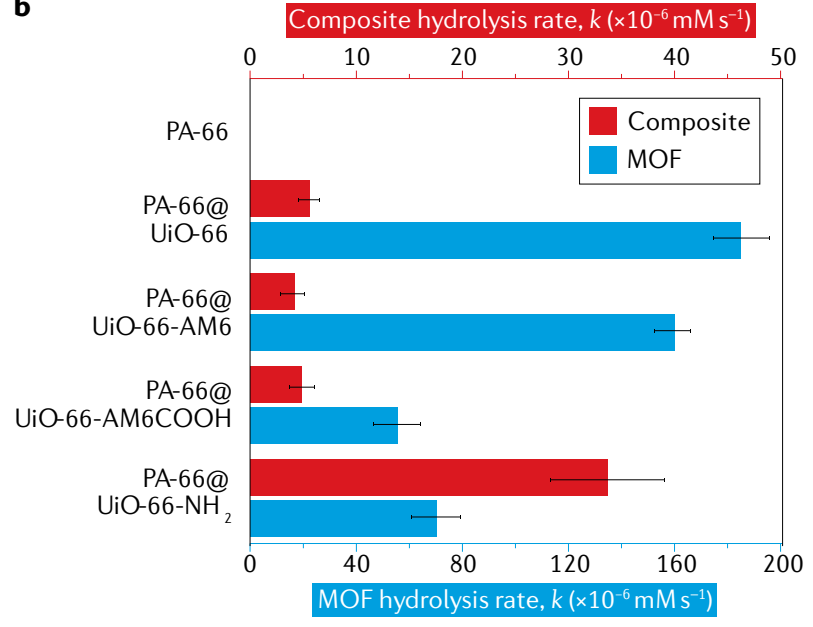

Fig. 8 | Metal-organic framework-nylon composites. a | Different metal-organic frameworks (MOFs) used for post-synthetic polymerization in nylon (PA-66) composites. b | Hydrolysis degradation rate of dimethyl $p$-nitrophenylphosphate by MOF powders and PA-66-MOF composites (measured by an ultraviolet-visible absorption at $407 \mathrm{~nm}$ ). Adapted with permission from REF. ${ }^{107}$, Wiley.

results show that it can be possible to produce PPE that can degrade CWAs. However, much shorter degradation times are needed in order to guarantee sufficient protection. Therefore, further research in this topic has focused on the introduction of other additives to MOF composites to increase activity. UiO-66 was also deposited on both polymethyl methacrylate (PMMA) and PMMA$\mathrm{Ti}(\mathrm{OH})_{4}$ and tested for the degradation of DMNP. In this work, it was shown that the composite outperformed the powdered MOF, which was attributed to the increased dispersion of the MOF within the fibre, overcoming the diffusion limitations. This work also showed that the inclusion of $\mathrm{Ti}(\mathrm{OH})_{4}$ decreases the half-life of DMNP even further, 29 versus $72 \mathrm{~min}$ compared with the PMMA-UiO-66 composite, and this was suggested to arise from the presence of both acidic and basic sites in the $\mathrm{Ti}(\mathrm{OH})_{4}\left(\right.$ REF. $\left.^{106}\right)$. In a similar way, UiO-66 was also added to a polymer solution and then incorporated to obtain the PVDF- Ti $(\mathrm{OH})_{4}-\mathrm{UiO}-66$ composite $^{103}$ (FIG. 7i). This MOF-fibre compound resulted in being more active than PVDF functionalized with the individual components ${ }^{103}$ (FIG. 7j). Triethanolamine (TEA) was also used to create a self-buffering, basic composite similar to the buffered solutions in which simulant tests are performed. However, only the degradation of the simulant required the addition of TEA. When this MOF-fibre composite was tested for the degradation of soman, higher activity was reported in the absence of TEA. This was attributed to the difference in P-F bond strength between the simulant and the agent.

One of the first examples of modified UiO-66 composites for the degradation of CWAs was proposed by López-Maya and co-workers, who enhanced the activity of $\mathrm{UiO}-66$ by the insertion of $\mathrm{LiO} t \mathrm{Bu}$ and investigated this for both nerve agent simulants (diisopropyl phosphorofluoridate (DIFP) and DMMP) and blister agent simulants (CEES) $)^{104}$. It was shown that the insertion of lithium alkoxide increases the hydrolysis for all three typical CWA bonds investigated: $\mathrm{P}-\mathrm{F}, \mathrm{P}-\mathrm{O}$ and $\mathrm{C}-\mathrm{Cl}$.
They prepared a MOF@silk composite by spraying a methanolic solution of $\mathrm{LiO} t \mathrm{Bu}-\mathrm{MOF}$ onto silk fibroin fibres and reported that DIFP, DMMP and CEES in contact with this composite exhibited half-lives of 20,50 and $8 \mathrm{~min}$, respectively.

More recently, UiO-66 MOFs were used to prepare a nylon-MOF composite through PSP for the breakdown of $\mathrm{DMNP}^{107}$. Nylon 6,6 is a polyamide polymer (PA-66) especially used in high-durability textiles and many plastic industries. The results show that the rate of DMNP degradation is almost three times higher for $\mathrm{UiO}-66$ and $\mathrm{UiO}-66-\mathrm{AM} 6$ powders compared with $\mathrm{UiO}-66-\mathrm{AM} 6 \mathrm{COOH}$ and $\mathrm{UiO}-66-\mathrm{NH}_{2}$. However, the incorporation of these MOFs into PA-66 composites also showed some promising results, with PA-66UiO-66- $\mathrm{NH}_{2}$ showing much higher activity compared with other cases in which UiO-66 is non-covalently incorporated into PA-66 (FIG. 8). Although these materials lose their catalytic activity after four cycles, these preliminary results are encouraging and the performances of these materials will need to be tested when engineered into textiles.

Similarly, a 2D water-stable $\mathrm{Cu}$-tetrakis (4-carboxyphenyl)porphyrin (TCPP) MOF with both polar and apolar characteristics and controlled crystal arrangement was deposited on PP fibre ${ }^{108}$. This specific MOF can capture water-immiscible toxins that are present in humid conditions, as well as polar toxins, owing to the presence of both hydrophobic porphyrin linkers and open coordination sites. The CEES uptake of the MOF under both humid ( $80 \%$ relative humidity) and dry conditions was about $3 \mathrm{~mol} \mathrm{~kg}{ }^{-1}$. The growth mechanism of the MOF on the fibre was not affected when submerged in water for $17 \mathrm{~h}$ at $25^{\circ} \mathrm{C}$ and Cu-TCPP maintained its original $2 \mathrm{D}$ structure, even after water treatment ${ }^{108}$. The uptake of polar molecule increases when the water uptake is higher because of the enhanced intermolecular hydrogen bonding between the polar molecule and the water film ${ }^{109}$. However, the water uptake of 
the $\mathrm{Cu}$-TCPP-fibre composite was found to be double compared with that of MOF in its powder form.

Another MOF that has been widely investigated for such applications is MOF-808, with the pioneering work of Omar Farha and colleagues leading to a spin-out company NuMat Technologies, which has successfully designed uniforms to absorb nerve agents ${ }^{110}$. NuMat is working with the US Army to produce PPE that also destroys CWAs ${ }^{110}$. Their first attempt to deposit MOF-808 coatings on polyester fibres for the capture of CEES and hydrolysis of GD was based on a three-phase growth mechanism that enabled a uniform coverage of the fibre ${ }^{111}$. A comparison of the activity of UiO-66$\mathrm{NH}_{2}$-fibre and MOF-808-fibre showed that the latter is ten times faster in the degradation of DMNP, owing to the more open $\mathrm{Zr}$ sites available for the reaction. Based on these findings, Farha and colleagues managed to incorporate MOF-808 onto polyethylenimine (PEI) fibre by simply mixing the MOF powder with ground PEI particles in a solution ${ }^{112}$. These textile materials maintained their catalytic activity and resisted real-life atmospheric conditions, such as humidity, atmospheric $\mathrm{CO}_{2}$, heavy contaminants (such as octane) and sweat ${ }^{112}$. While most research has been focused on UiO-MOFs for the degradation of CWAs and their simulants, more comparative studies are needed to verify the effectiveness of such catalysts compared with other MOFs.

A bio-inspired fabric using polydopamine (PDA) as a mediating layer between $\mathrm{UiO}-66-\mathrm{NH}_{2}$ and $\mathrm{PA}-6$ nanofibres for the degradation of DMNP has also been proposed. This self-detoxifying filter membrane can photothermally degrade DMNP when irradiated under simulated solar light, with $t_{1 / 2}=0.5 \mathrm{~min}\left(\mathrm{REF}^{113}\right)$. This shows that scientific research is making progress towards eco-friendly solutions to fight CWAs. Still, such improvements are not fully applicable to the designing of textiles for PPE when we consider other environmental conditions, such as in the absence of simulated solar light.

Even though these results sound promising, there are downsides to the use of simulants instead of the actual agents. Simulants are very suitable for experiments, because they are safer to work with and, at the same time, tend to mimic the behaviour of the actual agent. However, they often degrade faster than the actual agent in similar conditions. There are still a few unanswered questions concerning the long-term performance and the effectiveness of catalytically embedded fabric for PPE if they are constantly being exposed to such toxic chemicals. We assume that the duration of exposure, the type and the concentration of the warfare agents will have a major effect on the fabric or the material of construction of PPE. Still, previously mentioned findings are crucial steps towards the efficient implementation of MOFs in protective gear.

Class B PPE against CWAs are protective gear that repel CWAs but do not degrade them to safer by-products through routes such as hydrolysis. These adsorbants share many similarities to those discussed above, in that they are often based on MOFs grown on similar fibres or fabrics. The difference is that these materials either exploit the MOF's incredible microporous volume and ability to adsorb CWAs or they have been treated in such a way to create superhydrophobic surfaces that repel CWAs. While these are useful for the protection of the wearer, they are less desirable than materials that degrade CWAs, as the persistent threat of the CWA remains.

Military PPE is normally tested to check if the fabric can withstand CWAs. An Aerosol Vapour Liquid Assessment Group (AVLAG) test cell is used to measure the level of CWA permeation through the fabric. For example, the permeation of HD and GD through UiO-66- $\mathrm{NH}_{2}$ deposited on cotton fibres (16 and $5 \mu \mathrm{g} \mathrm{cm}^{-2}$ for HD and GD, respectively) resulted to be substantially hindered compared with pure cotton fibres (184 and $120 \mu \mathrm{g} \mathrm{cm}^{-2}$ for HD and GD, respectively $)^{114}$. Even though previously discussed studies have shown that UiO-66- $\mathrm{NH}_{2}$ can degrade CWA simulants, amine-functionalized MOFs tend to behave differently when in powder form or when integrated in fabric material. Furthermore, the effectiveness of these MOF-modified cotton fibres need to be tested in various climate conditions. Another cotton-fibre-based textile has been proposed for the simultaneous adsorption, sensing through a gradual visible colour change and degradation of the nerve agent simulant dimethyl chlorophosphate (DMCP). This smart textile consists of a combination of HKUST-1, a Cu-based MOF and graphitic carbon nitride in its oxidized form (gCNox), which resulted in a nanocomposite (MOFgCNox). The high dispersion of the MOF crystals within the textile and the addition of gCN promotes the activity of copper centres, allowing the adsorption of almost $7 \mathrm{~g}$ of DMCP per gram of $\mathrm{Cu}$. However, the morphology of the textile changed after three days of DMCP exposure ${ }^{115}$.

Although materials for the CWA absorption and repulsion serve a great purpose and any material that can safeguard the public against such attacks is a success, they suffer from some key drawbacks. The first is that they do not degrade CWAs, and, as a result, these dangerous molecules remain present. In the case of superhydrophobic materials, although the wearer is protected, CWAs will still end up running off onto surfaces or land. The persistence of such chemicals in the environment is addressed in the next section, but this then requires a secondary effort to remove or degrade these chemicals and, until removal, secondary exposure to such hazards may occur. The second downfall is one that has been discussed throughout this article, which is the issue of reusability. Once a fabric is full of CWA, it will need to be sent for thorough decontamination to remove or deactivate the CWA or there will need to be a special destruction procedure for such materials. Therefore, we argue that, although these materials have a vital role in protecting vulnerable populations against attack, they have limitations and are inferior to those materials that actively degrade the warfare agents whilst protecting the wearer.

Decontamination of land and surfaces after an attack with chemical toxins. We previously mentioned the extant danger of secondary exposure of toxic compounds on humans. In addition, animals and wildlife 
are also susceptible to certain forms of deadly agents. Specifically, domestic animals that live in proximity to human populations are affected by the same kind of threat. Maintaining a clean wildlife for a healthy food source as well as materials for garments and other necessities is crucial $^{116,117}$.

Organophosphates in particular are incredibly persistent in the environment, and their adsorption is often irreversible with a half-life of several years ${ }^{118}$. Parathion, for example, is an organophosphate compound that acts as an insecticide and has a $t_{1 / 2}$ of 16 years in soil ${ }^{119}$. This means that threat to humans and animals still exists long after an attack has happened. A recent example of how persistent and dangerous organophosphate-based nerve agents are after an attack can be seen after the Novichok attack in Salisbury, UK, where an attending police officer fell seriously ill and 48 other members of the public were assessed in hospital over the following days ${ }^{120}$. In this situation, there are two types of material that would be needed: wipes active for CWA degradation to clean surfaces and devices for removing persistent nerve agents from land and soil. Recent work has focused on using

Table 1 | Most recent applications of metal-organic frameworks-embedded textiles for the detoxification of some nerve agents and their simulants, and the blister agent simulant 2-chloroethyl ethyl sulfide

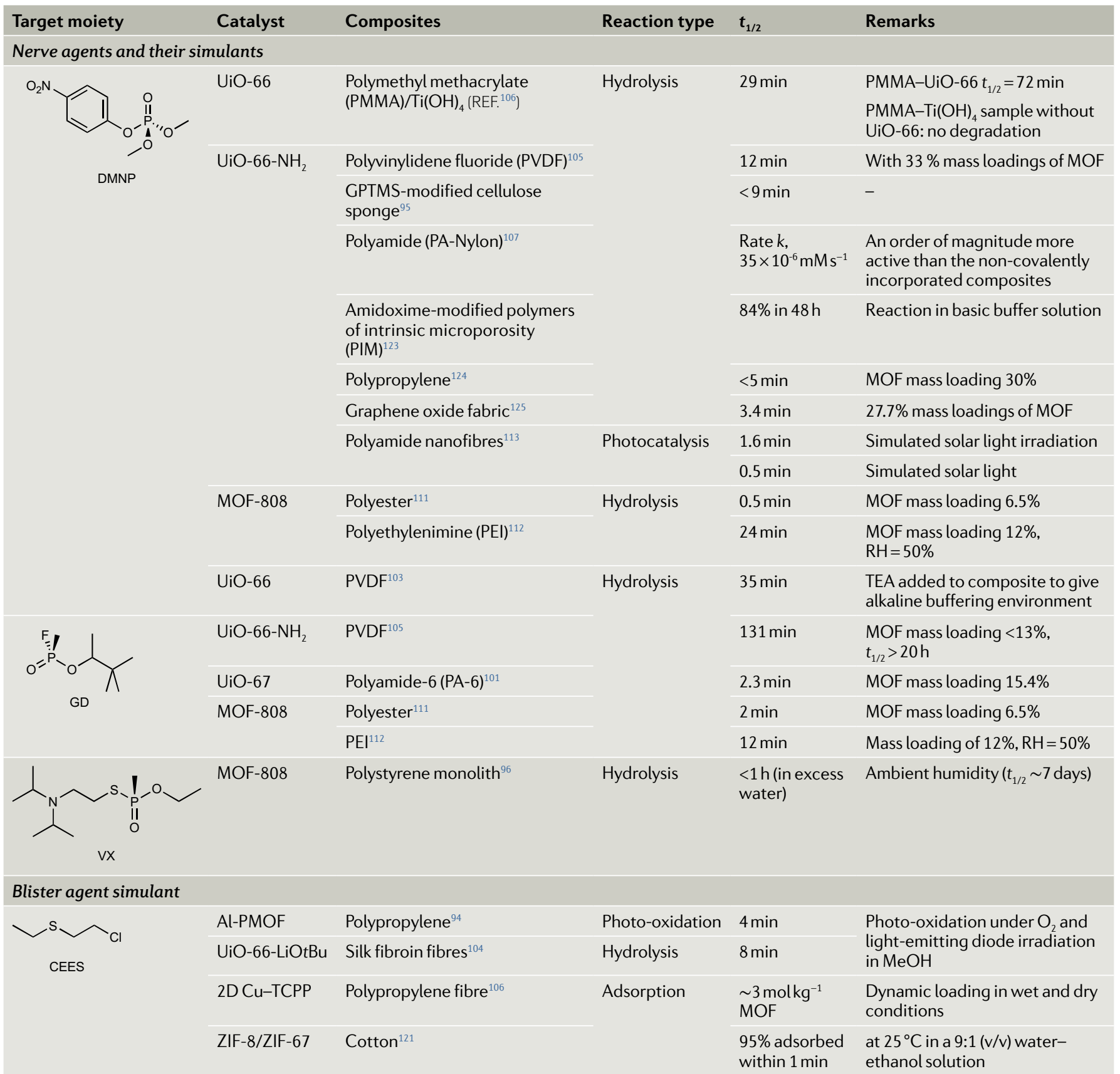

CEES, 2-chloroethyl ethyl sulfide; DMNP, dimethyl p-nitrophenylphosphate; GD, soman; GPTMS, $\gamma$-glycidoxypropyltrimethoxysilane; MOF, metal-organic framework; PMOF, porphyrin-based MOF; RH, relative humidity; $t_{1 / 2}$, half-life; TCPP, tetrakis(4-carboxyphenyl)porphyrin; TEA, triethanolamine; VX, venomous agent X; ZIF, zeolitic imidazolate framework. 


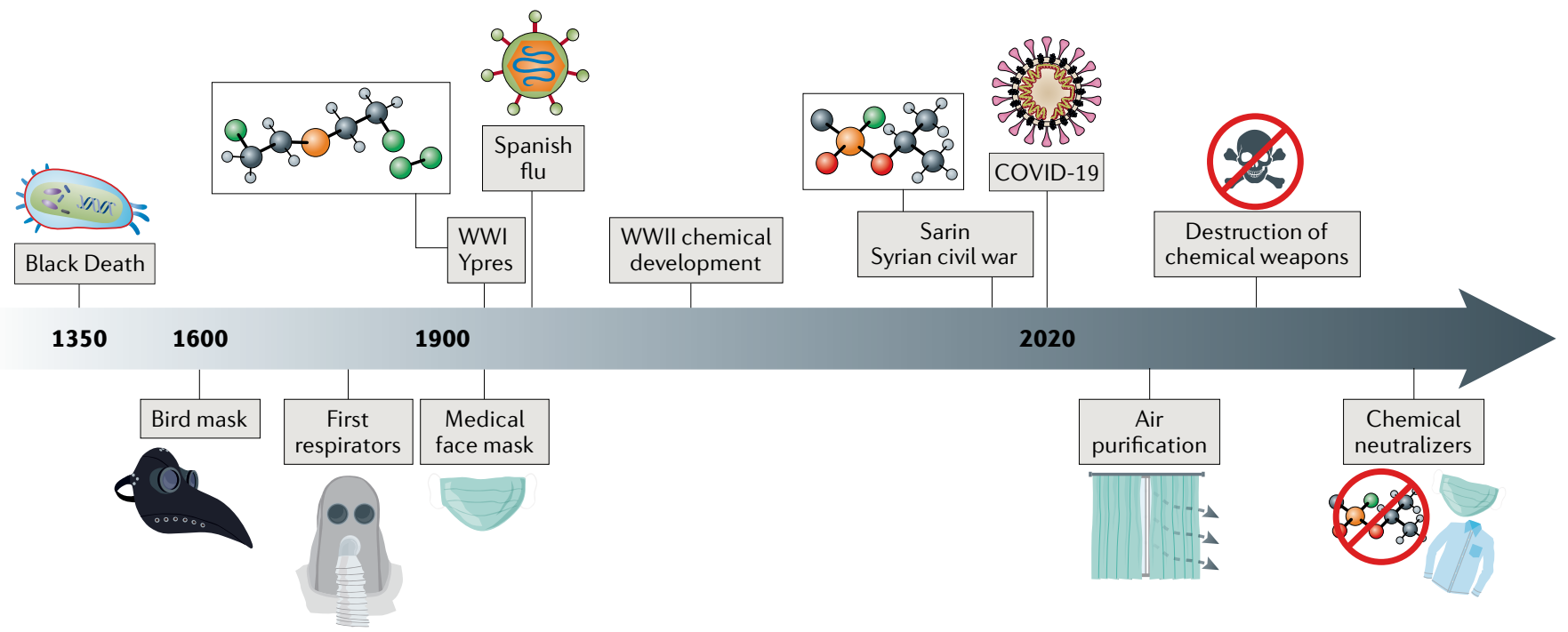

Fig. 9 | Timeline. This timeline summarizes some notable catastrophic events, the progress of protective equipment and presents a perspective on the future with fabrics and surfaces functionalized with chemical neutralizers that can self-detoxify biological and chemical toxins. WWI, World War I; WWII, World War II.

zeolitic imidazolate frameworks (ZIFs), a subclass of MOF with zeolitic topology, for the removal of blister agent simulant CEES and actual blister agent $\mathrm{HD}^{121}$. The specific ZIFs chosen (for example, ZIF-8 and ZIF-67) showed remarkable uptake and were subsequently integrated onto cotton wipes. It was shown that the wipes perform better under higher concentrations of water (in a 9:1 (v/v) water-ethanol solution) and can remove $95 \%$ of CEES within one minute. One of the downsides of this approach is that these wipes do not degrade HD, merely adsorb it. However they are reusable and were demonstrated to recover 95-100\% capacity after centrifuging in acetonitrile. This is promising, as it gives a pathway by which the site of an attack may be quickly and safely decontaminated, with the HD being destroyed at a secondary location.

TABLE 1 summarizes the most recent advancements on the incorporation of MOFs in textiles for the degradation of CWAs and their simulants, with the target moiety being the main focus of such application.

\section{Conclusions and perspective}

The timeline in FIG. 9 provides a summary of some notable events related to the exposure of mankind to biological and chemical toxins, including ways for their remediation. Ongoing research efforts are really needed to find reliable and promising solutions to the events related to both the unintentional and intentional exposure to biological and chemical toxins, as recently shown by the COVID-19 outbreak. Finding common ground between different types of toxins is essential, as we have seen that each application and catalyst material has a specific degradation pathway and that activity for one type of agent does not guarantee a similar activity for another. For example, a flax-based fabric functionalized with $\mathrm{CaO}$ nanoparticles has been initially synthesized for the degradation of both organophosphates and antibacterial activity ${ }^{122}$. Despite the positive degradation of DMNP under UV irradiation, no antibacterial activity was observed against both gram-positive (S. aureus) and gram-negative (E. coli) bacteria on $\mathrm{CaO}$-functionalized flax fabric. This example shows that, whether the catalyst material is a MOF or any other porous material, certain limitations are expected for each application. The ultimate goal is to be able to design a functional porous material that can detoxify both chemical and biological toxins in a fast and reliable manner.

Recent research has shown that MOFs offer an active and promising solution to degrade CWAs. However, the activity of these porous materials in a test tube or a small-scale lab experiment is often quite different from taking these into a war zone for active use. Zr-based MOFs show promise for efficient degradation of CWAs and their simulants. From the examples discussed in this Review, we realize that a good catalytic performance of MOFs lies in increasing pore volume, by creating defects that arise from decreasing connectivity. Furthermore, MOF-textile composites are still challenging to design and to maintain for long-term uses. However, scientific progress is being made on these aspects and more is to be expected in the near future.

Yet, bridging the gap between simulant-based experiments and real-world conditions remains a real challenge. Relevant environmental conditions encountered on a battlefield should be kept in mind when designing proper experimental tests. In addition, the detoxification of toxic agents should be fast and complete decomposition is required at ambient conditions. Realistic and human-friendly texture should also be considered when designing protective suits and clothing, as these fabrics will be worn for extended hours. Alongside the need to protect against chemical and biological toxins, general requirements include the following: waterproof, air permeability, insulation, low weight for easier movement and durability. The challenge still lies in designing a multifunctional protective suit that can detoxify both biological and chemical toxins, by simultaneously killing pathogens and degrading toxic chemicals in the 
most realistic conditions. A material needs to protect primary exposed victims and those who are affected by secondary exposure. Understanding the limitations of the catalyst material is important when designing such materials. Realizing functionalized materials that will protect against biological hazards faces the same challenges. MOFs again present an interesting solution, with their vast tunability. However, their manipulation onto fibres is still challenging and degradation through the leaching of metal ions leads to a loss of activity over time. Photocatalysts, such as doped $\mathrm{TiO}_{2}$, appear to offer the most promising path forward. Not only have these been shown to inactivate both bacteria and viruses but they can also absorb and degrade harmful chemicals. Photocatalysts do not rely on a leaching system, so they have longer lifetimes and, through doping or forming composites, can also exhibit tunable properties such as band gap and wettability. However, $\mathrm{TiO}_{2}$ mainly absorbs light in the UV region; therefore, work should focus towards more efficient absorption of visible light. As these materials work through the photogeneration of ROS and photoactive porphyrins feature in a number of MOFs active for CWAs, these linkers may provide the key to a more universal MOF that can provide antipathogenic protection, as well as clean-up of pollutants and protection from warfare threats.

Finally, we stress the importance of bridging the gap between materials science and chemical reactivity for the detoxification of some harmful chemicals and the need to create proper applications to disinfect common areas or to create surfaces that can self-detoxify for a safer living and working environment. Clearly, there is a lot that chemists can contribute to when materials science is combined in a clever way with catalysis science.

Published online 5 May 2021
1. Stevens, P. Diseases of Poverty and the 10/90 Gap (National Prevention Information Network ${ }^{\text {BETA, }}$ 2004)

2. Human Wrongs Watch. How air pollution is destroying our health. Human Wrongs Watch https://humanwrongs-watch.net/2019/06/04/how-air-pollutionis-destroying-our-health/ (2019).

3. Organisation for the Prohibition of Chemical Weapons. Convention on the Prohibition of the Development, Production and Stockpiling of Chemical Weapons and on their Destruction (2005).

4. Perper, R. Over 10,000 tear gas canisters have been fired in Hong Kong's vicious protests, and it could have long-term consequences for the city's health. Business Insider. https://www. businessinsider.com/expertslong-term-effects-tear-gas-exposure-hongkong-2020-1 (2020).

5. Dodd, V., Harding, L. \& MacAskill, E. Sergei Skripal: former Russian spy poisoned with nerve agent, say police. The Guardian. https://www.theguardian.com/ uk-news/2018/mar/07/russian-spy-police-appeal-forwitnesses-as-cobra-meeting-takes-place (2018).

6. BBC News. Syria war: What we know about Douma 'chemical attack'. BBC https://www.bbc.com/news/ world-middle-east-43697084 (2018).

7. Skurie, J. How does a gas mask protect against chemical warfare? National Geographic https://www. nationalgeographic.com/news/2013/9/130830-gasmasks-syria-israel-chemical-warfare/ (2013).

8. Giannakoudakis, D. A. \& Bandosz, T. J. in Detoxification of Chemical Warfare Agents Ch. 2 (Springer, 2017).

9. Eitzen, E. M., \& Takafuji, E. T. in Medical Aspects of Chemical and Biological Warfare Ch. 18 (Office of The Surgeon General Borden Institute, 1997).

10. Christopher, L. G. W. Biological warfare a historical perspective. J. Am. Medic. Assoc. 278, 412-417 (1997).

11. Riedel, S. Biological warfare and bioterrorism: a historical review. Bayl. Univ. Med. Cent. Proc. 17, 400-406 (2004).

12. Barras, V. \& Greub, G. History of biological warfare and bioterrorism. Clin. Microbiol. Infect. 20, 497-502 (2014)

13. World Health Organization. Cholera situation in Yemen: Governorate cases deaths CFR (2020).

14. Sondi, I. \& Salopek-Sondi, B. Silver nanoparticles as antimicrobial agent: a case study on E. coli as a model for Gram-negative bacteria. J. Colloid Interface Sci. 275, 177-182 (2004).

15. Fernandes, J. C. et al. Antimicrobial effects of chitosans and chitooligosaccharides, upon Staphylococcus aureus and Escherichia coli, in food model systems. Food Microbiol. 25, 922-928 (2008)

16. Guo, B., Pasco, E. V., Xagoraraki, I. \& Tarabara, V. V. Virus removal and inactivation in a hybrid microfiltration-UV process with a photocatalytic membrane. Sep. Purif. Technol. 149, 245-254 (2015).

17. Liga, M. V., Bryant, E. L., Colvin, V. L. \& Li, Q. Virus inactivation by silver doped titanium dioxide nanoparticles for drinking water treatment. Water Res. 45, 535-544 (2011).
18. Liga, M. V., Maguire-Boyle, S. J., Jafry, H. R., Barron, A. R. \& Li, Q. Silica decorated $\mathrm{TiO}_{2}$ for virus inactivation in drinking water - simple synthesis method and mechanisms of enhanced inactivation kinetics. Environ. Sci. Technol. 47, 6463-6470 (2013).

19. Han, J. et al. Efficient and quick inactivation of SARS coronavirus and other microbes exposed to the surfaces of some metal catalysts. Biomed. Environ. Sci. $18,176-180$ (2005)

20. Macomber, L. \& Imlay, J. A. The iron-sulfur clusters of dehydratases are primary intracellular targets of copper toxicity. Proc. Natl Acad. Sci. USA 106, 8344-8349 (2009).

21. Rao, P. V. \& Holm, R. H. Synthetic analogues of the active sites of iron-sulfur proteins. Chem. Rev. 104 527-559 (2004).

22. Chaturvedi, K. S \& Henderson, J. P. Pathogenic adaptations to host-derived antibacterial copper. Front. Cell. Infect. Microbiol. 4, 3 (2014).

23. Lemire, J. A., Harrison, J. J. \& Turner, R. J. Antimicrobial activity of metals: mechanisms, molecular targets and applications. Nat. Rev. Microbiol. 11, 371-384 (2013).

24. Stanić, V. et al. Synthesis, characterization and antimicrobial activity of copper and zinc-doped hydroxyapatite nanopowders. Appl. Surf. Sci. 256, 6083-6089 (2010).

25. He, H. et al. Catalytic inactivation of SARS coronavirus, Escherichia coli and yeast on solid surface. Catal. Commun. 5, 170-172 (2004).

26. Salleh, A. et al. The potential of silver nanoparticles for antiviral and antibacterial applications: a mechanism of action. Nanomaterials 10, 1566 (2020).

27. Elechiguerra, J. L. et al. Interaction of silver nanoparticles with HIV-1. J. Nanobiotechnol. 3, 6 (2005).

28. Pal, S., Tak, Y. K. \& Song, J. M. Does the antibacterial activity of silver nanoparticles depend on the shape of the nanoparticle? A study of the gram-negative bacterium Escherichia coli. Appl. Environ. Microbiol. 73, 1712-1720 (2007)

29. Prabhu, S. \& Poulose, E. K. Silver nanoparticles: mechanism of antimicrobial action, synthesis, medical applications, and toxicity effects. Int. Nano Lett. 2, 32 (2012).

30. Wang, C., Qian, X. \& An, X. In situ green preparation and antibacterial activity of copperbased metal-organic frameworks/cellulose fibers (HKUST-1/CF) composite. Cellulose 22, 3789-3797 (2015).

31. Rodríguez, H. S., Hinestroza, J. P., Ochoa-Puentes, C. Sierra, C. A. \& Soto, C. Y. Antibacterial activity against Escherichia coli of Cu-BTC (MOF-199) metal-organic framework immobilized onto cellulosic fibers. J. Appl. Polym. Sci. 131, 40815 (2014).

32. Tamames-Tabar, C. et al. A Zn azelate MOF: combining antibacterial effect. Cryst. Eng. Comm. 17, 456-462 (2015).

33. Aguado, S. et al. Antimicrobial activity of cobalt imidazolate metal-organic frameworks. Chemosphere 113, 188-192 (2014).
34. Berchel, M. et al. A silver-based metal-organic framework material as a 'reservoir' of bactericidal metal ions. New J. Chem 35, 1000-1003 (2011).

35. Restrepo, J. et al. An antibacterial Zn-MOF with hydrazinebenzoate linkers. Eur. J. Inorg. Chem. 2017, 574-580 (2017)

36. Liu, Y., Xu, X., Xia, Q., Yuan, G. \& Cui, Y. Multiple topological isomerism of three-connected networks in silver-based metal-organoboron frameworks. Chem. Commun. 46, 2608-2610 (2010).

37. Aryanejad, S., Bagherzade, G. \& Moudi, M. Green synthesis and characterization of novel Mn-MOFs with catalytic and antibacterial potentials. New J. Chem. 44, 1508-1516 (2020).

38. Zhang, D., Zhou, Y., Cuan, J. \& Gan, N. A lanthanide functionalized MOF hybrid for ratiometric luminescence detection of an anthrax biomarker. Cryst. Eng. Comm. 20, 1264-1270 (2018)

39. Emam, H. E., Darwesh, O. M. \& Abdelhameed, R. M. In-growth metal organic framework/synthetic hybrids as antimicrobial fabrics and its toxicity. Colloids Surf. B Biointerfaces 165, 219-228 (2018).

40. Quirós, J. et al. Antimicrobial metal-organic frameworks incorporated into electrospun fibers. Chem. Eng. J. 262, 189-197 (2015).

41. Fagan, R., McCormack, D. E., Dionysiou, D. D. \& Pillai, S. C. A review of solar and visible light active $\mathrm{TiO}_{2}$ photocatalysis for treating bacteria, cyanotoxins and contaminants of emerging concern. Mater. Sci. Semicond. Proc. 42, 2-14 (2016).

42. Fujishima, A., Zhang, X. \& Tryk, D. A. TiO photocatalysis and related surface phenomena. Surf. Sci. Rep. 63, 515-582 (2008).

43. Huang, Z. et al. Bactericidal mode of titanium dioxide photocatalysis. J. Photochem. Photobiol. A Chem. 130, 163-170 (2000).

44. Yu, J. C., Ho, W., Lin, J., Yip, H. \& Wong, P. K. Photocatalytic activity, antibacterial effect, and photoinduced hydrophilicity of $\mathrm{TiO}_{2}$ films coated on a stainless steel substrate. Environ. Sci. Technol. 37, 2296-2301 (2003).

45. Fang, F. C. Antimicrobial reactive oxygen and nitrogen species: Concepts and controversies. Nat. Rev. Microb. 2, 820-832 (2004).

46. Liu, Y., Wang, X., Yang, F. \& Yang, X. Excellent antimicrobial properties of mesoporous anatase $\mathrm{TiO}_{2}$ and $\mathrm{Ag} / \mathrm{TiO}{ }_{2}$ composite films. Microporous Mesoporous Mater. 114, 431-439 (2008).

47. Cho, M., Chung, H., Choi, W. \& Yoon, J. Different inactivation behaviors of MS-2 phage and Escherichia coli in $\mathrm{TiO}_{2}$ photocatalytic disinfection. Appl. Environ. Microbiol 71, 270-275 (2005).

48. Li, Q., Page, M. A., Mariñas, B. J. \& Shang, J. K. Treatment of coliphage MS2 with palladium-modified nitrogen-doped titanium oxide photocatalyst illuminated by visible light. Environ. Sci. Technol. 42, 6148-6153 (2008).

49. Sahariah, P. \& Másson, M. Antimicrobial chitosan and chitosan derivatives: a review of the structure-activity relationship. Biomacromolecules 18, 3846-3868 (2017). 
50. Duan, J., Park, S.-I., Daeschel, M. A. \& Zhao, Y. Antimicrobial chitosan-lysozyme (CL) films and coatings for enhancing microbial safety of mozzarella cheese. J. Food Sci. 72, M355-M362 (2007).

51. Chirkov, S. N. The antiviral activity of chitosan (review) Appl. Biochem. Microbiol. 38, 1-8 (2002).

52. Raut, A. V., Yadav, H. M., Gnanamani, A Pushpavanam, S. \& Pawar, S. H. Synthesis and characterization of chitosan- $\mathrm{TiO}_{2}$ : $\mathrm{Cu}$ nanocomposite and their enhanced antimicrobial activity with visible light. Colloids Surf. B Biointerfaces 148, 566-575 (2016).

53. Zhang, X. et al. Preparation of chitosan- $\mathrm{TiO}_{2}$ composite film with efficient antimicrobial activities under visible light for food packaging applications. Carbohydr. Polym. 169, 101-107 (2017).

54. Xu, Y., Wen, W. \& Wu, J.-M. Titania nanowires functionalized polyester fabrics with enhanced photocatalytic and antibacterial performances. J. Hazard. Mater. 343, 285-297 (2018).

55. Tahmasebizad, N., Hamedani, M. T. Shaban Ghazani, M. \& Pazhuhanfar, Y. Photocatalytic activity and antibacterial behavior of $\mathrm{TiO}_{2}$ coatings co-doped with copper and nitrogen via sol-gel method. J. Sol-Gel Sci. Technol. 93, 570-578 (2020).

56. Dai, W. X. et al. Influence of $\mathrm{pH}$ value of $\mathrm{TiO}_{2}$ sol on surface gloss of corresponding $\mathrm{TiO}_{2}$ film coated on ceramic tiles. Surf. Eng. 25, 106-110 (2009).

57. van Doremalen, N. et al. Aerosol and surface stability of SARS-CoV-2 as compared with SARS-CoV-1. N. Engl. J. Med. 382, 1564-1567 (2020).

58. Ornstein, J. et al. SARS-CoV-2 inactivation potential of metal organic framework induced photocatalysis. Preprint at medRxiv https://doi.org/10.1101/ 2020.10.01.20204214 (2020).

59. Lan, G. et al. Titanium-based nanoscale metal-organic framework for type I photodynamic therapy. J. Am Chem. Soc. 141, 4204-4208 (2019).

60. Alzate-Sánchez, D. M., Smith, B. J., Alsbaiee, A. Hinestroza, J. P. \& Dichtel, W. R. Cotton fabric functionalized with a $\beta$-cyclodextrin polymer captures organic pollutants from contaminated air and water. Chem. Mater. 28, 8340-8346 (2016)

61. Cohen, N. Ikea curtains break down pollutants, highlight interest in fabric purifiers. Tech Xplore https://techxplore.com/news/2019-02-ikeacurtains-pollutants-highlight-fabric.html (2019)

62. Howarth, A. J., Majewski, M. B. \& Farha, O. K. in Metal-Organic Frameworks (MOFs) for Environmental Applications Ch 6. 179-202 (Elsevier, 2019).

63. Liu, Y. et al. Catalytic degradation of chemical warfare agents and their simulants by metal-organic frameworks. Coord. Chem. Rev. 346, 101-111 (2017).

64. Islamoglu, T. et al. Metal-organic frameworks against toxic chemicals. Chem. Rev. 120, 8130-8160 (2020).

65. Kirlikovali, K. O., Chen, Z., Islamoglu, T., Hupp, J. T. \& Farha, O. K. Zirconium-based metal-organic frameworks for the catalytic hydrolysis of organophosphorus nerve agents. ACS Appl. Mater. Interfaces 12, 14702-14720 (2020).

66. Grissom, T. G. et al. Metal-organic framework- and polyoxometalate-based sorbents for the uptake and destruction of chemical warfare agents. ACS Appl. Mater. Interfaces 12, 14641-14661 (2020).

67. Decoste, J. B. \& Peterson, G. W. Metal-organic frameworks for air purification of toxic chemicals. Chem. Rev. 114, 5695-5727 (2014).

68. Liu, Y. et al. Efficient and selective oxidation of sulfur mustard using singlet oxygen generated by a pyrene based metal-organic framework. J. Mater. Chem. A 4 13809-13813 (2016).

69. Agrawal, M., Gallis, D. F. S., Greathouse, J. A. ¿ Sholl, D. S. How useful are common simulants of chemical warfare agents at predicting adsorption behavior? J. Phys. Chem. C 122, 26061-26069 (2018)

70. Newmark, J. Nerve agents. Neurologist 13, 20-32 (2007).

71. Mercey, G. et al. Reactivators of acetylcholinesterase inhibited by organophosphorus nerve agents. Acc. Chem. Res. 45, 756-766 (2012).

72. Szinicz, L. History of chemical and biological warfare agents. Toxicology 214, 167-181 (2005)

73. Talmage, S. S., Watson, A. P., Hauschild, V., Munro, N. B. $\&$ King, J. Chemical warfare agent degradation and decontamination. Curr. Org. Chem. 11, 285-298 (2007).
74. Zou, R. et al. A porous metal-organic replica of $\alpha-\mathrm{PbO}_{2}$ for capture of nerve agent surrogate. J. Am. Chem. Soc. 132, 17996-17999 (2010)

75. Bromberg, L. et al. Alkylaminopyridine-modified aluminum aminoterephthalate metal-organic frameworks as components of reactive self-detoxifying materials. ACS Appl. Mater. Interfaces 4, 4595-4602 (2012).

76. Jiang, H., Feng, D., Liu, T., Li, J. J. \& Zhou, H. J. Pore surface engineering with controlled loadings of functional groups via click chemistry in highly stable metal-organic frameworks. J. Am. Chem. Soc. 134 14690-14693 (2012).

77. Balow, R. B. et al. Environmental effects on zirconium hydroxide nanoparticles and chemical warfare agent decomposition: implications of atmospheric water and carbon dioxide. ACS Appl. Mater. Interfaces 9 , 39747-39757 (2017).

78. Klet, R. C., Liu, Y., Wang, T. C., Hupp, T. \& Farha, O. K. Evaluation of Brønsted acidity and proton topology in $\mathrm{Zr}$ - and $\mathrm{Hf}$-based metal-organic frameworks using potentiometric acid-base titration. J. Mater. Chem . A 4. 1479-1485 (2016)

79. Howarth, A. J. et al. Chemical, thermal and mechanical stabilities of metal-organic frameworks. Nat. Rev. Mater. 1, 15018 (2016)

80. Troya, D. Reaction mechanism of nerve-agent decomposition with $\mathrm{Zr}$-based metal organic frameworks. J. Phys. Chem. C 120, 29312-29323 (2016).

81. Katz, M. J. et al. Simple and compelling biomimetic metal-organic framework catalyst for the degradation of nerve agent simulants. Angew. Chem. Int. Ed. 53 497-501 (2014)

82. Katz, M. J. et al. Exploiting parameter space in MOFs: a 20-fold enhancement of phosphate-ester hydrolysis with UiO-66- $\mathrm{NH}_{2}$. Chem. Sci. 6 , 2286-2291 (2015)

83. Ryu, S. G. et al. Availability of Zr-based MOFs for the degradation of nerve agents in all humidity conditions. Microporous Mesoporous Mater. 274. 9-16 (2019)

84. de Koning, M. C., van Grol, M. \& Breijaert, T Degradation of paraoxon and the chemical warfare agents $\mathrm{VX}$, tabun, and soman by the metal-organic frameworks UiO-66- $\mathrm{NH}_{2}$, MOF-808, NU-1000, and PCN-777. Inorg. Chem. 56, 11804-11809 (2017).

85. de Koning, M. C., Peterson, G. W., Van Grol, M. Iordanov, I. \& McEntee, M. Degradation and detection of the nerve agent $\mathrm{VX}$ by a chromophore-functionalized zirconium MOF. Chem. Mater. 31, 7417-7424 (2019).

86. Khateri, S., Ghanei, M., Keshavarz, S., Soroush, M. \& Haines, D. Incidence of lung, eye, and skin lesions as late complications in 34,000 Iranians with wartime exposure to mustard agent. J. Occup. Environ. Med. 45, 1136-1143 (2003)

87. Munro, N. B. et al. The sources, fate, and toxicity of chemical warfare agent degradation products. Environ Health Perspect. 107, 933-974 (1999).

88. Weetman, C., Notman, S. \& Arnold, P. L. Destruction of chemical warfare agent simulants by air and moisture stable metal NHC complexes. Dalton Trans. 47, 2568-2574 (2018)

89. Roy, A. et al. Kinetics of degradation of sulfur mustard and sarin simulants on HKUST-1 metal organic framework. Dalton Trans. 41, 12346-12348 (2012).

90. Kumar, V. \& Anslyn, E. V. A selective and sensitive chromogenic and fluorogenic detection of a sulfur mustard simulant. Chem. Sci. 4, 4292-4297 (2013).

91. Pereira, C. F. et al. Detoxification of a mustard-gas simulant by nanosized porphyrin-based metal-organic frameworks. ACS Appl. Nano Mater. 2, 465-469 (2019).

92. Liu, Y., Moon, S., Hupp, J. T. \& Farha, O K. Dual-function metal-organic framework as a versatile catalyst for detoxifying chemical warfare agent simulants. ACS Nano 9, 12358-12364 (2015).

93. Son, F. A. et al. Uncovering the role of metal-organic framework topology on the capture and reactivity of chemical warfare agents. Chem. Mater. 32 4609-4617 (2020).

94. Lee, D. T., Jamir, J. D., Peterson, G. W. \& Parsons, G. N. Protective fabrics: metal-organic framework textiles for rapid photocatalytic sulfur mustard simulant detoxification. Matter 2, 404-415 (2020).

95. Shen, C. et al. Catalytic MOF-loaded cellulose sponge for rapid degradation of chemical warfare agents simulant Carbohydr. Polym. 213, 184-191 (2019).

96. Kalinovskyy, Y. et al. Swell and destroy: a metalorganic framework-containing polymer sponge that immobilizes and catalytically degrades nerve agents. ACS Appl. Mater. Interfaces 12, 8634-8641 (2020).

97. Organisation for the Prohibition of Chemical Weapons. Practical Guide for Medical Management of Chemical Warfare Casualties (Organisation for the Prohibition of Chemical Weapons, 2019).

98. Cowsar, D. R., Dunn, R. L. \& Casper, R. A. Process for decontaminating military nerve and blister agents. US Patent US4784699A (1988)

99. Phadatare, A. \& Kandasubramanian, B. Metal organic framework functionalized fabrics for detoxification of chemical warfare agents. Ind. Eng. Chem. Res. 59, 569-586 (2020).

100. Ma, K. et al. Fiber composites of metal-organic frameworks. Chem. Mater. 32, 7120-7140 (2020).

101. Zhao, J. et al. Ultra-fast degradation of chemical warfare agents using MOF-nanofiber kebabs. Angew. Chem. Int. Ed. 55, 13224-13228 (2016).

102. Kalaj, M. \& Cohen, S. M. Spray-coating of catalytically Active MOF-polythiourea through postsynthetic polymerization. Angew. Chem. Int. Ed. $\mathbf{5 9}$ 13984-13989 (2020)

103. Dwyer, D. et al. Chemical protective textiles of UiO-66 integrated PVDF composite fibers with rapid heterogeneous decontamination of toxic organophosphates. ACS Appl. Mater. Interfaces 10 34585-34591 (2018)

104. López-Maya, E. et al. Textile/metal-organic-framework composites as self-detoxifying filters for chemicalwarfare agents. Angew. Chem. Int. Ed. 54, 6790-6794 (2015).

105. Lu, A. X. et al. MOFabric: electrospun nanofiber mats from PVDF/UiO-66- $\mathrm{NH}_{2}$ for chemical protection and decontamination. ACS Appl. Mater. Interfaces 9 , 13632-13636 (2017)

106. McCarthy, D. L et al. Electrospun metal-organic framework polymer composites for the catalytic degradation of methyl paraoxon. New J. Chem. 41, 8748-8753 (2017).

107. Kalaj, M., Denny, M. S., Bentz, K. C., Palomba, J. M. $\&$ Cohen, S. M. Nylon-MOF composites through postsynthetic polymerization. Angew. Chem. Int. Ed. 58, 2336-2340 (2019).

108. Lee, D. T., Jamir, J. D., Peterson, G. W. \& Parsons, G. N. Water-stable chemical-protective textiles via euhedral surface-oriented 2D Cu-TCPP metal-organic frameworks. Small 15, 1805133 (2019).

109. Xu, G., Otsubo, K., Yamada, T., Sakaida, S $\&$ Kitagawa, H. Superprotonic conductivity in a highly oriented crystalline metal-organic framework nanofilm. J. Am. Chem. Soc. 135, 7438-7441 (2013).

110. Chen, S. This cloth destroys deadly nerve agents in minutes. WIRED https://www.wired.com/story/ this-cloth-destroys-deadly-nerve-agents/ (2020).

111. Ma, K. et al. Scalable and template-free aqueous synthesis of zirconium-based metal-organic framework coating on textile fiber. J. Am. Chem. Soc. 141 15626-15633 (2019).

112. Chen, Z. et al. Integration of metal-organic frameworks on protective layers for destruction of nerve agents under relevant conditions. J. Am. Chem. Soc. 141, 20016-20021 (2019).

113. Yao, A., Jiao, X., Chen, D. \& Li, C. Bio-inspired polydopamine-mediated Zr-MOF fabrics for sola photothermal-driven instantaneous detoxification of chemical warfare agent simulants. ACS Appl. Mater Interfaces 12, 18437-18445 (2020).

114. Kim, M. K., Kim, S. H., Park, M., Ryu, S. G. \& Jung, H. Degradation of chemical warfare agents over cotton fabric functionalized with UiO-66- $\mathrm{NH}_{2}$. RSC Adv. 8, 41633-41638 (2018)

115. Giannakoudakis, D. A., Hu, Y., Florent, M. \& Bandosz, T. J. Smart textiles of MOF/g- $\mathrm{C}_{3} \mathrm{~N}_{4}$ nanospheres for the rapid detection/detoxification of chemical warfare agents. Nanoscale Horiz. 2 356-364 (2017)

116. Wismer, T. in Handbook of Toxicology of Chemical Warfare Agents 721-738 (Elsevier, 2009).

117. Coppock, R. W. in Handbook of Toxicology of Chemical Warfare Agents 747-751 (Elsevier, 2009)

118. Ragnarsdottir, K. V. Environmental fate and toxicology of organophosphate pesticides. J. Geol. Soc. 157, 859-876 (2000)

119. Stewart, D. K. R., Chisholm, D. \& Ragab, M. T. H. Long term persistence of parathion in soil. Nature 229, 47 (1971). 
120. BBC News Russian spy poisoning: What we know so far. BBC https://www.bbc.com/news/uk-43315636 (2018)

121. Son, Y. R., Ryu, S. G. \& Kim, H. S. Rapid adsorption and removal of sulfur mustard with zeolitic imidazolate frameworks ZIF-8 and ZIF-67. Microporous Mesoporous Mater. 293, 109819 (2020).

122. Pereira, J. F., Ferreira, D. P., Pinho, E. \& Fangueiro, R. Chemical and biological warfare protection and self-decontaminating flax fabrics based on $\mathrm{CaO}$ nanoparticles. Key Eng. Mater. 812 75-83 (2019).

123. Jung, D. et al. Reactive porous polymers for detoxification of a chemical warfare agent simulant. Chem. Mater. 32, 9299-9306 (2020).

124. Lee, D. T., Zhao, J., Peterson, G. W. \& Parsons, G. N. Catalytic "MOF-Cloth" formed via directed supramolecular assembly of UiO-66- $\mathrm{NH}_{2}$ crystals on atomic layer deposition-coated textiles for rapid degradation of chemical warfare agent simulants. Chem. Mater 29, 4894-4903 (2017).

125. Song, L. et al. Photothermal graphene/UiO-66- $\mathrm{NH}_{2}$ fabrics for ultrafast catalytic degradation of chemical warfare agent simulants. J. Hazard. Mater. 393 122332 (2020).

\section{Acknowledgements}

This work is part of the Advanced Research Center for Chemical Building Blocks, ARC CBBC, which is co-founded and co-financed by the Netherlands Organisation for Scientific Research (NWO) and the Netherlands Ministry of Economic Affairs and Climate Policy. This work was supported by the Netherlands Center for Multiscale Catalytic Energy Conversion (MCEC), an NWO Gravitation programme funded by the Ministry of Education, Culture and Science of the government of the Netherlands and the US Army Research Office (ARO), and the European Union's Horizon 2020 research and innovation programme under the Marie Skłodowska-Curie grant agreement no. 801359. The authors thank T. Hartman (Utrecht University) for the graphical illustrations.

\section{Author contributions}

B.M.W. conceived the theme. C.R.J. and L.A.P. contributed equally to the writing of the manuscript. E.M.H. and B.M.W. contributed with insights and discussions. All authors contributed data and insights, and discussed and edited the manuscript.

\section{Competing interests}

The authors declare no competing interests.

Peer review information

Nature Reviews Chemistry thanks the anonymous reviewers for their contribution to the peer review of this work.

\section{Publisher's note}

Springer Nature remains neutral with regard to jurisdictional claims in published maps and institutional affiliations.

\section{RELATED LINKS}

Chemical warfare agents: https://www.un.org/disarmament/ wmd/chemical/

Ebola virus disease: https://www.who.int/en/news-room/

fact-sheets/detail/ebola-virus-disease

NuMat Technologies: https://www.numat-tech.com/ OPCW: https://www.opcw.org/media-centre/opcw-numbers OPCW Article IV Chemical Weapons: https://www.opcw.org/ chemical-weapons-convention/articles/article-iv-chemicalweapons

OPCW by the numbers: https://www.opcw.org/media-centre/ opcw-numbers

The Nobel Peace Prize for 2013: https://www.nobelprize.org/ prizes/peace/2013/press-release/

The National Center for Emerging and Zoonotic Infectious Diseases (NCEZID) Bioterrorism Agents/Diseases: https:// emergency.cdc.gov/agent/agentlist-category.asp

United Nations Office for Disarmament Affairs: https://

www.un.org/disarmament/wmd/chemical/

West African Ebola outbreak of 2013-2016: https://www. who.int/en/news-room/fact-sheets/detail/ebola-virus-disease

(c) Springer Nature Limited 2021, corrected publication 2021 